\title{
Accumulation of Cytoplasmic DNA Due to ATM Deficiency Activates the Microglial Viral Response System with Neurotoxic Consequences
}

\author{
Xuan Song, ${ }^{1,2}$ Fulin Ma, ${ }^{1,2}$ and $\odot$ Karl Herrup ${ }^{1,2}$ \\ ${ }^{1}$ Division of Life Science, and ${ }^{2}$ State Key Laboratory of Molecular Neuroscience, The Hong Kong University of Science and Technology, Clear Water Bay, \\ Hong Kong 999077
}

ATM (ataxia-telangiectasia mutated) is a PI3K-like kinase best known for its role in the DNA damage response (DDR), especially after double-strand breaks. Mutations in the ATM gene result in a condition known as ataxia-telangiectasia (A-T) that is characterized by cancer predisposition, radiosensitivity, neurodegeneration, sterility, and acquired immune deficiency. We show here that the innate immune system is not spared in A-T. ATM-deficient microglia adopt an active phenotype that includes the overproduction of proinflammatory cytokines that are toxic to cultured neurons and likely contribute to A-T neurodegeneration. Causatively, ATM dysfunction results in the accumulation of DNA in the cytoplasm of microglia as well as a variety of other cell types. In microglia, cytoplasmic DNA primes an antiviral response via the DNA sensor, STING (stimulator of interferon genes). The importance of this response pathway is supported by our finding that inhibition of STING blocks the overproduction of neurotoxic cytokines. Cytosolic DNA also activates the AIM2 (absent in melanoma 2) containing inflammasome and induces proteolytic processing of cytokine precursors such as pro-IL-1 $\beta$. Our study furthers our understanding of neurodegeneration in A-T and highlights the role of cytosolic DNA in the innate immune response.

Key words: AIM2; inflammation; microglia; neurotoxicity; STING

\section{Significance Statement}

Conventionally, the immune deficiencies found in ataxia-telangiectasia (A-T) patients are viewed as defects of the B and T cells of the acquired immune system. In this study, we demonstrate the microglia of the innate immune system are also affected and uncover the mechanism by which this occurs. Loss of ATM (ataxia-telangiectasia mutated) activity leads to a slowing of DNA repair and an accumulation of cytoplasmic fragments of genomic DNA. This ectopic DNA induces the antivirus response, which triggers the production of neurotoxic cytokines. This expands our understanding of the neurodegeneration found in A-T and offers potentially new therapeutic options.

\section{Introduction}

ATM (ataxia-telangiectasia mutated) is a large PI3K family protein kinase that is prominently involved in the response to DNA

\footnotetext{
Received April 5, 2019; revised May 29, 2019; accepted June 3, 2019.

Author contributions: X.S. and K.H. designed research; X.S. and F.M. performed research; X.S. and K.H. analyzed data; X.S. wrote the first draft of the paper; X.S., F.M., and K.H. edited the paper; X.S. wrote the paper.

This work was supported by The Hong Kong University of Science and Technology (Grant R9321) and the Research Grants Council of the Hong Kong SAR (Grants 16101315, 16124916, (6009-17G, and AoE/M-604/16). We thank Hei-Man Chow and Kai-Hei Tse for advice and discussions, Jianping Ren for help with animal breeding and genotyping, Aifang Cheng for technical guidance, Beika Zhu for neuronal culture, and Yan Huang for the subcellular fractionation.

The authors declare no competing financial interests.

K. Herrup's present address: Department of Neurobiology, University of Pittsburgh School of Medicine, Pittsburgh, PA.

Correspondence should be addressed to Karl Herrup at herrup@ust.hk.
}

double-strand breaks (Banin et al., 1998; Bosotti et al., 2000; Shiloh, 2003; Lee and Paull, 2007). ATM is recruited to the break site, where it undergoes autophosphorylation and activation (Bakkenist and Kastan, 2003; Kurz and Lees-Miller, 2004). It then phosphorylates a number of different proteins that go on to slow cellular processes such as cell division and enhance DNA repair. Mutations in ATM cause a rare multisystemic disease known as ataxia telangiectasia (A-T), in which the ataxia is ascribed to a profound cerebellar Purkinje cell degeneration (Crawford et al., 2000). Persons with A-T also suffer from eye and skin telangiectasias (Paller et al., 1991; Farr et al., 2002; Shiloh, 2003), cancer (Renwick et al., 2006; Reiman et al., 2011), and immune system

https://doi.org/10.1523/JNEUROSCI.0774-19.2019

Copyright $\odot 2019$ the authors 
dysfunction (Peterson and Kelly, 1964; McFarlin et al., 1972; Nowak-Wegrzyn et al., 2004). The latter is associated with a failure of both T- and B-cell development (Bosotti et al., 2000; Lumsden et al., 2004; Matei et al., 2006; Schatz and Swanson, 2011; Driessen et al., 2013; Mraz et al., 2013; Chaudhary and AlBaradie, 2014; Chessa et al., 2016). This failure is a logical consequence of an inefficient double-strand break repair process as ATM has been shown to be important for $\mathrm{V}(\mathrm{D}) \mathrm{J}$ recombination (Bredemeyer et al., 2006, 2008; Bagley et al., 2007).

As a consequence of this clear connection between DNA damage repair and one of the prominent $\mathrm{A}-\mathrm{T}$ symptoms, most immunobiological studies of A-T focus on the role of ATM in T and B cells and the resulting defects in acquired immunity that occur in its absence (Lavin et al., 2007). However, this historical focus on the acquired immune response downplays the potential impact of ATM deficiency on the more primitive responses of the cells of the innate immune system: macrophages in the periphery and microglia in the brain. (Perlman et al., 2003). That ATM has a potential role here has suggested itself in part because antiinflammatory strategies targeting the innate immune system have proven effective in improving the neurological symptoms of human A-T and its mouse models. Further, ATM inhibition has been shown to upregulate inflammatory pathways of the innate immune system (Petersen et al., 2012) (Hartlova et al., 2015). Both A-T patients and $\mathrm{Atm}^{-/-}$animal models have higher serum levels of proinflammatory cytokines and other inflammatory markers than control subjects (Westbrook and Schiestl, 2010; Yang et al., 2014; Hui and Herrup, 2015; Quek et al., 2017a,b). These results and others suggest that the innate immune system does not escape the problems created by ATM deficiency and also point to a potentially important link between neurodegeneration of A-T and the inflammatory environment. This potential of establishing such a linkage is high because our understanding of the origins of the neurological symptoms in A-T remains rudimentary. In other neurodegenerative diseases, activation of the innate immune system is strongly implicated, Alzheimer's disease being the best known example (Combs et al., 1999; Wu et al., 2000; McGeer and McGeer, 2015). There are already hints that neuroinflammation is involved in A-T, especially in cerebellum (Yang et al., 2014; Hui and Herrup, 2015; Quek et al., 2017a,b).

We report here new findings that link the neurological symptoms of A-T directly to the inefficient DNA damage repair that occurs in innate immune cells with ATM deficiency. We show that ATM dysfunction causes an accumulation of cytosolic DNA that triggers an antiviral immune response in brain microglia. We show that this response relies on the cytoplasmic DNA sensor STING, as well as signaling through the AIM2-containing inflammasome. The result is the enhanced production and processing of proinflammatory cytokines such as IL- $1 \beta$. These are released as neurotoxic compounds that may account for many of the neurological symptoms found in A-T.

\section{Materials and Methods}

Animals. C57BL/6J wild-type mice and Atm ${ }^{-1-}$ mice, Bal (B6;129S4-

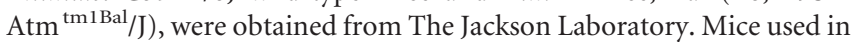
this study were maintained and bred in the Animal and Plant Care Facility of The Hong Kong University of Science and Technology (HKUST). Colonies were maintained by intercrossing heterozygous $\mathrm{Atm}^{+/-}$males and $\mathrm{Atm}^{+/-}$females. Protocols were approved by the Animal Ethics Committee at HKUST and their care was in according with both the institutional and Hong Kong guidelines. Genotyping of $\mathrm{Atm}^{-1-}$ mice was done with the PCR ReadyMix Kit (E3004; Sigma-Aldrich) using the following PCR primers: PGK35: 5' -GGA AAA GCG CCT CCC CTA CCC-
3'; Bal AT9: 5' -CCT CCT CAT ATT TGT AAC ACG CTG-3'; Bal AT12: 5'-TGT AAT GTG CCT TAA AGA ACC TGG-3'.

Reagents and molecular biologicals. The ATM-specific kinase inhibitor KU-60019 (S1570) was from Selleckchem. CCCP (a STING inhibitor, HY-10094) was from MedChemExpress. Recombinant IL-1RA (Animal-Free, 714406) was from BioLegend. Etoposide, a topoisomerase inhibitor, was from Sigma-Aldrich (33419-42-0). GFPTrex1-shRNA (TL511298) was from Origene. tGFP-STING-shRNA (TRCN0000346319) was from Sigma-Aldrich, MISSION shRNA Plasmid DNA. mtagBFP- STING (102586) was from Addgene.

Primary neuronal culture. Embryonic cortical neurons were isolated following standard procedures as described previously. Cortices were collected from embryonic day 16.5 (E16.5) C57BL/6J mouse embryos followed by $1 \times$ trypsin digestion in $37^{\circ} \mathrm{C}$ for $10 \mathrm{~min}$. The cells were cultured in Neurobasal medium (Thermo Fisher Scientific), supplemented with 2\% B27 (Thermo Fisher Scientific), 1\% Glutamax (Thermo Fisher Scientific), and $1 \%$ penicillin-streptomycin $(10,000 \mathrm{U} / \mathrm{ml}$; Thermo Fisher Scientific), in a $37^{\circ} \mathrm{C}$ incubator gassed with $5 \% \mathrm{CO}_{2} / 95 \%$ air. Neurons were plated at a final density of $8500 \mathrm{cells} / \mathrm{cm}^{2}$ on poly-Llysine-coated glass coverslips or in larger tissue culture plates (Thermo Fisher Scientific). For histological studies, cells were washed with PBS and fixed in 4\% paraformaldehyde (PFA, P6148-500G; Sigma-Aldrich) for $15 \mathrm{~min}$. After rinsing in PBS, cells were stored in $0.1 \%$ PFA if longerterm storage was required.

Primary microglial culture and preparation of conditioned media. Primary microglia were isolated from C57BL/6J mice. A mixed glial cell population was obtained from the cerebellum of P5 pups and was cultured for 2 weeks in T75 flasks with DMEM medium supplemented with $10 \% \mathrm{FBS}$ and $1 \%$ penicillin-streptomycin $(10,000 \mathrm{U} / \mathrm{ml}$; Thermo Fisher Scientific). Pure microglia were obtained by shaking the flasks at $37^{\circ} \mathrm{C}$ for $4 \mathrm{~h}$. The enriched population of microglia was then plated on poly-Llysine-coated glass coverslips at a final density of 50,000 cells per well in a 24 -well plate or 200,000 cells per well in poly-L lysine-coated 6-well plates and grown for $24 \mathrm{~h}$. The medium was then changed to serum free media for another $12 \mathrm{~h}$ before any treatment. KU-60019 conditioned medium was prepared by incubating microglia cells in Neurobasal medium containing $1 \mu \mathrm{M}$ KU-60019 (KM) for $48 \mathrm{~h}$. In the control group, microglia were exposed to Neurobasal medium without KU-60019 (MM). After a two-day treatment, the medium was centrifuged to remove cells and debris, then used for neuronal treatment within $24 \mathrm{~h}$. Microglia and neuron coculture system was established based on the previous work (Halle et al., 2008). Briefly, microglia and neurons from wild-type mice were cultured separately for $14 \mathrm{~d}$. Pure microglia were obtained by shaking the flasks at $37^{\circ} \mathrm{C}$ for $4 \mathrm{~h}$. Coculture system was built by plating microglia into the established neuronal culture with Neurobasal medium. The ratio between microglia and neurons is one to five considering the percentage of microglia in the brain. In experiments requiring analysis of the microglia themselves, cells in six-well plates were washed by PBS once and lysed with ice-cold RIPA buffer (EMD Millipore) together with $1 \times$ PhosSTOP phosphatase inhibitor mixture (Roche Applied Science) and $1 \times$ complete protease inhibitor mixture (Roche Applied Science). Cell lysate was then stored in $-80^{\circ} \mathrm{C}$ for further use. Cells in 24-well plates were rinsed with PBS and then fixed with $4 \%$ PFA for 15 min at room temperature. After rinsing once with PBS, cells were stored at $4^{\circ} \mathrm{C}$ in $\mathrm{PBS}$ for short times or with $0.1 \%$ PFA for longer times.

Cell culture and transfection. Human fibroblasts were obtained from Coriell Institute (Camden, NJ). Cells were cultured in DMEM supplemented with $15 \%$ FBS and $1 \%$ penicillin-streptomycin $(10,000 \mathrm{U} / \mathrm{ml}$; Thermo Fisher Scientific). Before using for analysis, cells were rinsed once with PBS and fixed by 15 min incubation in 4\% PFA. HEK293FT cells (Thermo Fisher Scientific) were cultured in DMEM supplemented with $10 \%$ FBS and $1 \%$ penicillin-streptomycin $(10,000 \mathrm{U} / \mathrm{ml}$; Thermo Fisher Scientific) at $37^{\circ} \mathrm{C}$ in a humidified incubator with $5 \% \mathrm{CO}_{2} / 95 \%$ air. Cells were plated in the density of 100,000 cells per well into a 6-well plate or 20,000 cells per well on a $13 \mathrm{~mm}$ coverslips in 24 -well plate and let grow for $24 \mathrm{~h}$ until cultures were $65 \%$ confluent. $1 \%$ penicillin-streptomycin $(10,000 \mathrm{U} / \mathrm{ml}$; Thermo Fisher Scientific) was removed from the media right before the transfection. DNA constructs were transfected 
with Lipofectamine 2000 (Thermo Fisher Scientific). Twelve hours after transfection, the transfection culture medium was replaced with fresh DMEM supplemented with $10 \%$ FBS and $1 \%$ penicillin-streptomycin. Cells were cultured for another $48 \mathrm{~h}$ (HEK293T) to allow recovery and plasmid expression. Before being used for analysis, cells were rinsed once with PBS. For histological studies, cells were fixed with 4\% PFA for 15 min and stored in $4^{\circ} \mathrm{C}$ for further use. For Flow Cytometry analysis, cells were fixed with $80 \%$ methanol in PBS for 15 min and stained with primary antibodies.

Tissue preparation and histochemistry. Mice were deeply anesthetized by intraperitoneal administration of $1.25 \%$ ice-cold Avertin (tribromoethanol, Sigma-Aldrich, $30 \mathrm{ml} / \mathrm{kg}$ ) and then perfused transcardially with cold PBS for $5 \mathrm{~min}$. After perfusion, the whole brain was dissected free of the skull and bisected along the midline. Half of the brain was snapfrozen in dry ice and stored at $-80^{\circ} \mathrm{C}$ for isolation of protein, DNA or RNA, and the other half was immerse-fixed in $4 \%$ PFA at $4^{\circ} \mathrm{C}$ overnight. After washing twice with PBS, the half brain was transferred to a $30 \%$ sucrose solution for another $24 \mathrm{~h}$ incubation at $4^{\circ} \mathrm{C}$. Each brain was embedded in Shandon Cryomatrix Frozen Embedding Medium (6769006; Thermo Fisher Scientific) and then quickly frozen on powdered dry ice. Ten-micron cryostat sections (CryoStar NX70; Thermo Fisher Scientific) were mounted on precoated SuperPlus glass slides and allowed to air dry overnight before storing in $-80^{\circ} \mathrm{C}$.

Annexin V/propidium iodide (PI) apoptotic assay. Apoptotic and necrotic events in cell culture were assayed by Annexin V/PI (V13245, Life Technologies) following the manufacturer's protocol. In brief, living cells on coverslips were rinsed once with cold PBS and immediately incubated with working solution containing PI and Alexa Fluor 488 Annexin $\mathrm{V}$ for $15 \mathrm{~min}$ in room temperature. After washing with Annexinbinding buffer, coverslips were mounted with Hydromount (HS-106; National Diagnostics) for fluorescent microscope imaging. Slides were examined under a fluorescent microscope (Olympus, BX53) with $20 \times$ [UPlanSApo, 0.75 numerical aperture (NA), Olympus] and $40 \times$ (UPlanSApo, $0.95 \mathrm{NA}$, Olympus) objectives. Fluorescence was equipped with an X-Cite120Q light source (Excelitas) Images were captured with a DP80 camera (Olympus). Overall intensity of Annexin V signal and PI signal was measured with ImageJ.

Immunocytochemistry and immunofluorescence. Immunocytochemistry was performed on $10 \mu \mathrm{m}$ mouse brain cryosections or PFA-fixed cells according to standard methods. Sections were rinsed with PBS three times followed by antigen retrieval achieved by a $10 \mathrm{~min}$ incubation at $95^{\circ} \mathrm{C}$ in citrate buffer (10 mu citric acid/0.05\% Tween 20 , pH 6.0). Sections were cooled to room temperature and then blocked in PBS with 5\% donkey serum and $0.1 \%$ Triton $\mathrm{X}-100$ for $1 \mathrm{~h}$ at room temperature. They were then incubated in the same solution with primary antibodies overnight at $4^{\circ} \mathrm{C}$. After rinsing with PBS three times, cells were immersed in fluorescent secondary antibodies, Alexa Fluor 488, 555, or 647 fluorescent dye (Life Technologies), for $1 \mathrm{~h}$ at room temperature. After counterstaining with DAPI (4',6-diamidino-2-phenylindole, dihydrochloride, Sigma-Aldrich) for $5 \mathrm{~min}$, sections were rinsed with PBS three times. All sections were then mounted with antifading fluorescence medium (Vector Laboratories) under a glass coverslip.

Coverslips with cultured cells were first rinsed with PBS and fixed in $4 \%$ PFA for $15 \mathrm{~min}$ at room temperature. Coverslips were then removed from PFA and rinsed with PBS for one time. After incubation in PBS with $5 \%$ donkey serum and $0.1 \%$ Triton $\mathrm{X}-100$ for $1 \mathrm{~h}$ at room temperature, primary antibodies were mixed in blocking buffer, and applied to the coverslips at $4^{\circ} \mathrm{C}$ overnight. Coverslips were then rinsed three times with PBS for 10 min each and incubated with the appropriate secondary antibodies at room temperature for $1 \mathrm{~h}$. After counterstaining with DAPI for $5 \mathrm{~min}$, coverslips were mounted with Hydromount (HS-106; National Diagnostics) for fluorescent microscope imaging. Coverslips and brain sections were examined under a fluorescent microscope. Images were captured with a DP80 camera (Olympus).

TUNEL assay and quantification. The TUNEL (Terminal dUTP Nick End Labeling) assay was performed on primary microglia using Click-iT Plus TUNEL Assay kit (C10617, Thermo Fisher Scientific) following the manufacturer's protocol. Primary microglia, which were cultured on 13 mm coverslips, were washed once with PBS and then fixed by incubation for $15 \mathrm{~min}$ in 4\% PFA at room temperature. After permeabilization at room temperature for $15 \mathrm{~min}$ and rinsing once in $\mathrm{PBS}$, TdT reaction buffer was applied to the coverslips for $10 \mathrm{~min}$ at $37^{\circ} \mathrm{C}$. Following that, TdT reaction mixture was applied to the slides and incubated for $60 \mathrm{~min}$ at $37^{\circ} \mathrm{C}$. After rinsing with deionized water, slides were blocked with $3 \%$ BSA and $0.1 \%$ Triton X-100 in PBS for 5 min. After rinsing with deionized water again, $50 \mu \mathrm{l}$ of the Click-iT Plus TUNEL reaction mixture was applied to each slide and allowed to spread completely over the surface. The slides were incubated in the dark for $30 \mathrm{~min}$ at $37^{\circ} \mathrm{C}$. After washing with PBS, slides were counterstained with DAPI and mounted with $\mathrm{Hy}$ dromount (HS-106; National Diagnostics) for fluorescent microscope imaging. The boundary of cells and nuclei were marked with Fiji using the free-hand tracing tool. The intensity of the TUNEL signal in the cytoplasm and the DAPI intensity in the nucleus were measured with ImageJ.

$q R T$-PCR. Microglia were lysed in buffer containing 3\% $\beta$-mercaptoethanol; total RNA was then extracted using RNeasy Mini Kit (Qiagen) following the established protocol. RNA was reverse-transcribed using High-Capacity cDNA Reverse Transcription Kit. The resulting cDNA was then analyzed by qRT-PCR using SYBR Green PCR Master Mix (Applied Biosystems) on the LightCycler 480 Instrument II (Roche Diagnostics). Following a $15 \mathrm{~min}$ 'hot start' at $95^{\circ} \mathrm{C}, 40$ cycles of the following program were performed: melting: $15 \mathrm{~s}$ at $94^{\circ} \mathrm{C}$, annealing: $30 \mathrm{~s}$ at $55^{\circ} \mathrm{C}$, and extension: $30 \mathrm{~s}$ at $70^{\circ} \mathrm{C}$. Melting curves were examined at the end of every round to ensure a single PCR product was produced with the certain melting temperature and primers. Data were analyzed using the comparative $\mathrm{Ct}$ method ( ${ }^{\Delta \Delta} \mathrm{Ct}$ method). Expression levels of Gapdh were used for normalization. The following primers $\left(5^{\prime}\right.$ to $\left.3^{\prime}\right)$ were designed on Primer-Blast and listed below: Arg11 forward: TCCTGAAGC CGAGAACCAAC, reverse: CTGTGAAGCGGCAGTCACTA; Yml forward: CCCAGGAAGTACCCTATGCC, reverse: GACCACGGCACCTC CTAAAT; Cxcl10 forward: GTCTGAGTGGGACTCAAGGG, reverse: CAACACGTGGGCAGGATAGG; Il-12 forward: CTCACCCTTAG GACCCAGGA, reverse: GTGTGGGTATGGTTCGGAGG; Il-1 $\beta$ forward: GCCACCTTTTGACAGTGATGAG, reverse: AAGGTCCACGGG AAAGACAC; $\operatorname{Tnf} \alpha$ forward: AGGCACTCCCCCAAAAGATG, reverse: CCACTTGGTGGTTTGTGAGTG; Ccl2 forward: GCTGTAGTTTTT GTCACCAAGCTC, reverse: AGTGCTTGAGGTGGTTGTGG; Il-6 forward: AGACAAAGCCAGAGTCCTTCAG, reverse: TGTGACTCCAGC TTATCTCTTGG; Gapdh forward: GGCAAATTCAACGGCACAGT, reverse: GGCCTCACCCCATTTGATGT.

Purification of cytoplasmic DNA. Cytoplasmic DNA was isolated as described previously with minor modifications (Yang et al., 2007). Microglia were lysed in $10 \mathrm{~mm}$ HEPES, pH 7.9, $10 \mathrm{~mm} \mathrm{KCl,} 1.5 \mathrm{~mm} \mathrm{MgCl}_{2}$, $0.34 \mathrm{~m}$ sucrose, $10 \%(\mathrm{v} / \mathrm{v})$ glycerol, plus protease inhibitors for $5 \mathrm{~min}$ on ice with $0.1 \%(\mathrm{v} / \mathrm{v})$ Triton X-100, and nuclei were removed by low-speed centrifugation $(1500 \mathrm{~g}, 10 \mathrm{~min})$. Cytoplasmic extracts were treated with 1 $\mathrm{mg} / \mathrm{ml}$ Proteinase $\mathrm{K}$ at $56^{\circ} \mathrm{C}$ for $2 \mathrm{~h}$ to remove protein. After phenol/ chloroform extraction, the aqueous supernatant was incubated with 500 $\mathrm{mg} / \mathrm{ml}$ DNase-free RNase A (QIAGEN) for $30 \mathrm{~min}$ at $37^{\circ} \mathrm{C}$ again followed by phenol/chloroform extraction. The DNA-containing aqueous phase was precipitated, resuspended in TE buffer, DNA concentrations were adjusted according to the protein concentration of cytoplasmic fractions and analyzed on a $2 \%$ agarose gel infused with ethidium bromide. The DNA concentration was determined by Qubit Assays.

Immunoprecipitation, subcellular fractionation, protein precipitation, SDS/PAGE, and Western blot analysis. Cultured cells were harvested with ice-cold RIPA buffer (EMD Millipore) with $1 \times$ PhosSTOP phosphatase inhibitor mixture (Roche Applied Science) and $1 \times$ complete protease inhibitor mixture (Roche Applied Science). The homogenate was then centrifuged at $4^{\circ} \mathrm{C}$ for $20 \mathrm{~min}$ at $21,000 \times \mathrm{g}$. The protein concentration of the supernatant was determined by the Bradford assay (Bio-Rad). For immunoprecipitation, $1 \mathrm{mg}$ of total protein was incubated with control IgG (Santa Cruz Biotechnology) for $30 \mathrm{~min}$ and precleared with $50 \mu \mathrm{l}$ of Dynabeads (Invitrogen). The mixture was then incubated with primary antibodies at $4^{\circ} \mathrm{C}$ overnight. After incubation, beads were collected with DynaMag-2 magnets (Life Technologies) and washed three times with RIPA buffer. Precipitated proteins were eluted in $50 \mu \mathrm{l}$ of $4 \times$ bromophe- 


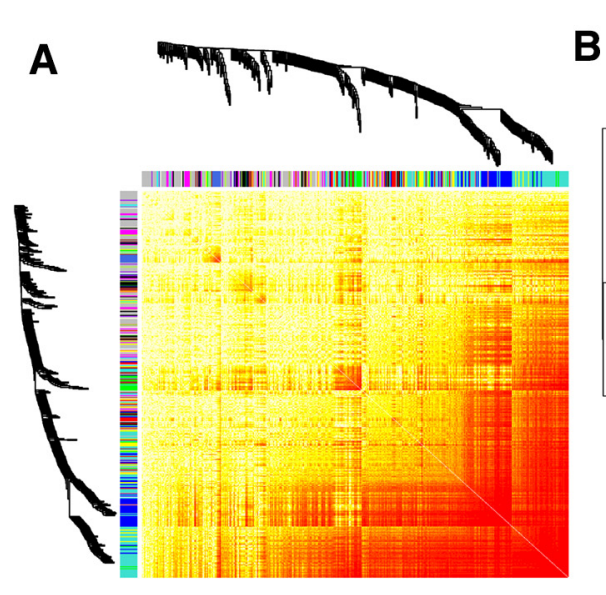

C
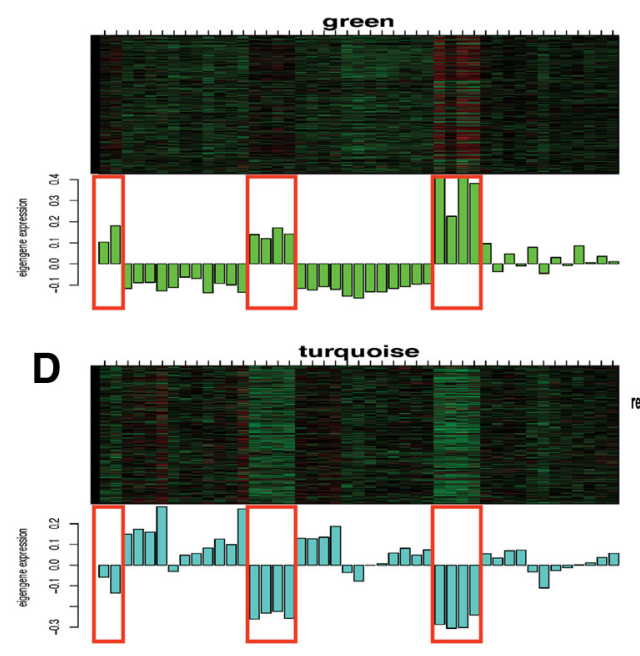
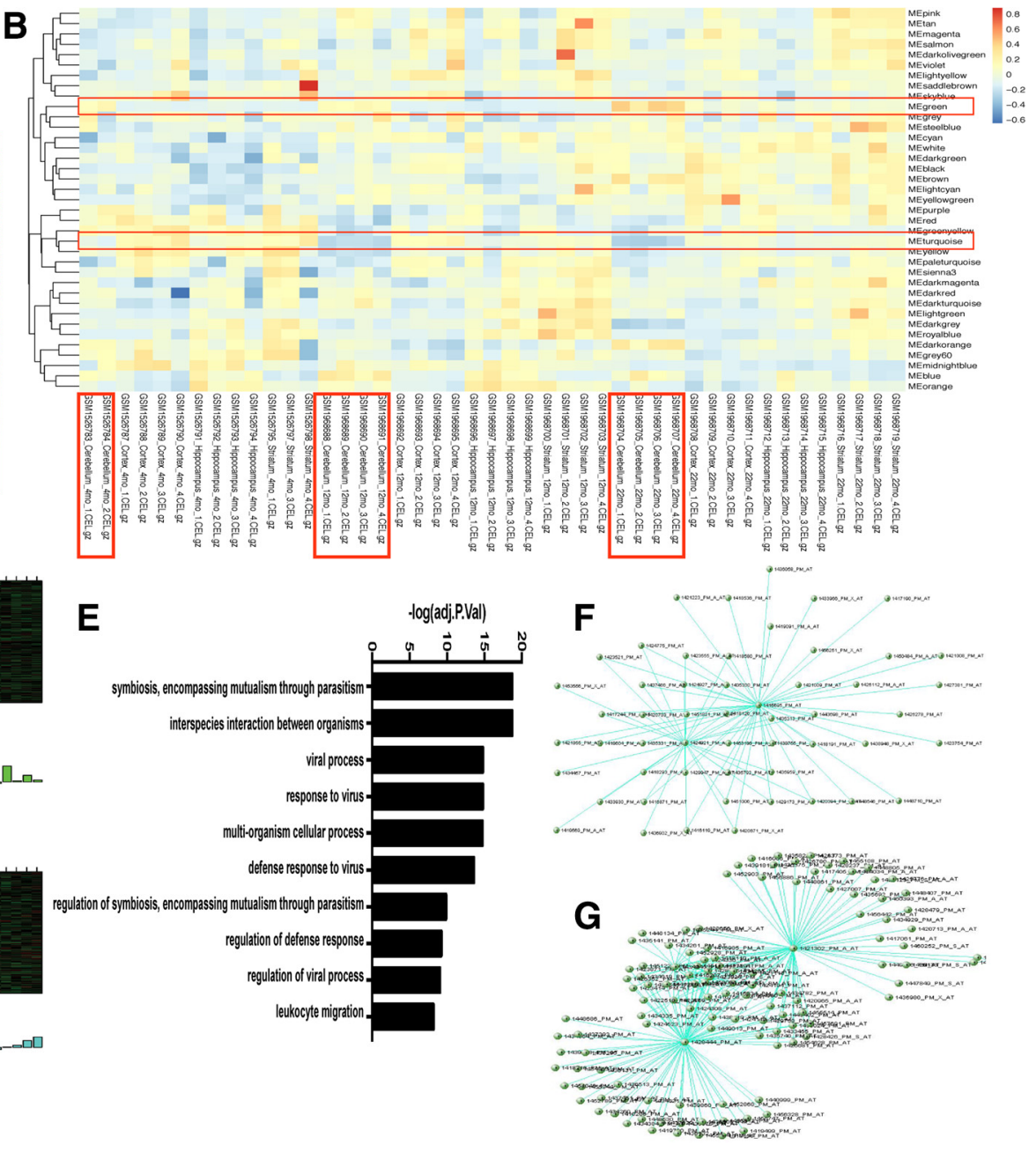

Figure 1. Cerebellar-specific microglia transcriptomic features. $\boldsymbol{A}$, Weighted gene coexpression network from microglial microarray data containing 45 samples from different regions of the brain. $\boldsymbol{B}$, Modules detected by measuring the topological overlap dissimilarity. $\boldsymbol{C}$, Cerebellar-specific upregulated genes. $\boldsymbol{D}$, Cerebellar-specific downregulated genes. $\boldsymbol{E}$, GO terms of cerebellarspecific upregulated genes. $\boldsymbol{F}$, Network and key drivers of cerebellar specific upregulated genes. $\mathbf{G}$, Network and key drivers of cerebellar-specific downregulated genes.

nol blue dye with $\beta$-mercaptoethanol and $150 \mu$ l of RIPA buffer. The eluted proteins were then analyzed by SDS/PAGE.

For subcellular fractionation, ER membranes were purified on discontinuous sucrose gradients as described previously (Williamson et al., 2015). Cells were lysed in MTE buffer (0.27 mannitol, $10 \mathrm{~mm}$ Tris-HCl, $0.1 \mathrm{~mm}$ EDTA, pH 7.4) by sonication. Lysed cells were centrifuged at $15,000 \times g$ for $10 \mathrm{~min}$ to pellet the nuclei, mitochondria and cellular debris while the supernatant was used for purification of ER fractions. The supernatant was layered on a discontinuous sucrose gradient consisting of $1.3 \mathrm{M}, 1.5 \mathrm{M}$ and $2.0 \mathrm{M}$ sucrose, and banded by centrifugation at $100,000 \times \mathrm{g}$ for $70 \mathrm{~min}$ at $4^{\circ} \mathrm{C}$. The ER fraction was collected at the interface between the supernatant and the $1.3 \mathrm{~m}$ sucrose layer and pelleted by centrifugation at $100,000 \times \mathrm{g}$ for $45 \mathrm{~min}$ at $4^{\circ} \mathrm{C}$. The ER fraction was then resuspended in PBS and used for Western blot analysis.

For protein precipitation from conditioned media, culture medium was harvested as described previously (Scheiblich et al., 2017). Protein was precipitated by adding an equal volume of methanol and a $1 / 4$ volume of chloroform. Precipitate was pelleted by centrifugation at $20,000 \times \mathrm{g}$ for $10 \mathrm{~min}$ at $4^{\circ} \mathrm{C}$. The pellet was resuspended in $500 \mu \mathrm{l}$ methanol and vortexed for $20 \mathrm{~s}$. After centrifugation at $20,000 \times \mathrm{g}$ for $10 \mathrm{~min}$, the liquid phase was removed. The pellet was dried at $55^{\circ} \mathrm{C}$ for $10 \mathrm{~min}$ and resuspended in $4 \times$ bromophenol blue dye with $\beta$-mercaptoethanol and stored at $-80^{\circ} \mathrm{C}$ for future use.

For Western blots, a total of $20 \mu \mathrm{g}$ of protein was separated by SDS/ PAGE and transferred to Immuno-Blot PVDF membranes (Bio-Rad). After blocking with nonfat milk, membranes were incubated with pri- mary antibodies at room temperature overnight. After rinsing with TBST three times, membranes were incubated with secondary antibodies for $1 \mathrm{~h}$ at room temperature. Signals were visualized with SuperSignal West Pico, Dura, or Femto chemiluminescent substrate (Thermo Fisher Scientific).

Flow cytometry analysis. Microglia or HEK293 cells were fixed in $80 \%$ methanol in PBS for $15 \mathrm{~min}$ at room temperature. Cells were pelleted by centrifugation $(800 \times g, 5 \mathrm{~min})$. Methanol was removed and cells were resuspended with blocking buffer (PBS with $0.1 \%$ Triton X-100 and 5\% donkey serum). After blocking for $1 \mathrm{~h}$ at room temperature, primary antibody against ssDNA, dsDNA or phospho-p65 was applied for $2 \mathrm{~h}$ at $4^{\circ} \mathrm{C}$. Washing was performed by topping up to $1 \mathrm{ml}$ with blocking buffer. Appropriate secondary antibodies were applied for another $1 \mathrm{~h}$ at $4^{\circ} \mathrm{C}$ followed by rinsing one time. FACS analysis of labeled cells was performed and analyzed by a BD Biosciences FACSAria IIIu flow cytometer using $70 \mu \mathrm{m}$ nozzle and equipped with $405,488,561$, and $631 \mathrm{~nm}$ lasers. Data were analyzed with FlowJo version 10.

Weighted correlation network analysis (WGCNA). Mouse microglial transcriptome data were obtained from the public genomics data repository Gene Expression Omnibus (GSE62420) (Grabert et al., 2016). To create this dataset, we isolated microglia from four different regions of the mouse brain, cerebellum, cortex, hippocampus, and striatum, at three different ages (Fig. 1) with flow cytometry. Total RNA was isolated from the purified microglia and used for microarray analysis. The method for network construction was described previously (Langfelder and Horvath, 2008). The absolute value of the Pearson correlation coef- 
ficient was used for all pairs of gene-expression values across 45 microarray samples. The Pearson correlation matrix was then transformed into an adjacency matrix resulting in a weighted network. Topological overlap for weighted networks was defined by the established formula (Langfelder and Horvath, 2008). Modules were detected by measuring the topological overlap dissimilarity (1 - topological overlap) in average linkage hierarchical clustering.

Statistical analysis. All data were obtained from at least three independent biological replicates as indicated. Quantifications were performed in a blinded manner. Differences between groups were measured using the unpaired $t$ test, one-way ANOVA, or multiple $t$ tests. Two-way ANOVA was used to determine the difference of two predicted variables. All statistical analyses were performed with GraphPad Prism 7. $p \leq 0.05$ was considered significant. In the figures, significance is indicated as follows: ${ }^{\star} p<0.05,{ }^{* *} p<0.01,{ }^{* * *} p<0.001$, and ${ }^{\star * *} p<0.0001$. Results are reported as mean $\pm \mathrm{SEM}$.

\section{Results}

\section{ATM dysfunction results in microglial hyperactivation}

Though previous work has showed the effect of ATM deficiency on cerebellar Purkinje cells (Chen et al., 2003; Jiang et al., 2015), the consequences for microglia have been less fully explored. To examine this issue, we mined a published microglia microarray dataset (GSE62420) assembled from different ages and different regions of the mouse brain, including cortex, hippocampus, striatum and cerebellum (Grabert et al., 2016). WGCNA of upregulated and downregulated microglial genes revealed a strong signal from the cerebellum that appeared in an age-dependent manner (Fig. 1A-D). Gene Ontology (GO) analysis of the genes that were upregulated in cerebellum showed that antiviral innate immune response-related genes were significantly overrepresented (Fig. 1E). Further analysis identified Tspo and Bst2 as core genes of the upregulated modules (Fig. $1 F$ ), both are essential players in neuroinflammation and the innate immune response (Evans et al., 2010; Royer and Carr, 2016; Crawshaw and Robertson, 2017). Asb2, a gene involved in cytokine suppression, was identified as the core gene of the downregulated module (Fig. $1 G)$. The identification of the cerebellum as a focus of the brain inflammatory environment as well as the neuronal phenotype of A-T led us to further explore the role of microglia-neuron interaction in the process of Purkinje cell degeneration.

Our previous work showed that ATM-deficient animals are hypersensitive to inflammatory stimuli such as LPS (Yang et al., 2014; Hui and Herrup, 2015; Hui et al., 2018). We first validated and extended these earlier observations on the state of microglia activation in our ATM-deficient mouse model. Immunostaining with the microglia-specific marker Ibal revealed substantial morphological variation in the cerebellar microglia from $\mathrm{Atm}^{-/-}$ mice (Fig. $2 A, B$ ). In the normal brain, microglia possess many fine processes, which allows the cell to extensively explore their environment. This can be referred as a "resting" state of microglia (Boche et al., 2013). Upon stimulation, however, microglia adopt a different morphology, which can be characterized by a larger spherical shape, with fewer but thicker processes (Boche et al., 2013). In wild-type animals, most microglia are found in the resting state with thin processes with small, round cell bodies. In $\mathrm{Atm}^{-/-}$mice by contrast, we found most microglia had shorter thicker processes and a larger cell body- all indicators of activation (Kongsui et al., 2014; Torres-Platas et al., 2014). Quantification of the images from nine animals of each genotype confirmed the increased percentage of activated microglia in the ATMdeficient mice (Fig. 2C,D). These findings were further extended in vitro. We used an ATM-specific kinase inhibitor, KU-60019, to blocked ATM activity. We found that $1 \mu \mathrm{M}$ of the drug was suf- ficient to reduce the activation of ATM with few nonspecific effects as measured by decreased levels of p-ATM (ab81292, 1:1000), p-Chk2 (CST 2661S, 1:1000), p-p53 (CST 9284S, $1: 1000)$, and $\gamma \mathrm{H} 2 \mathrm{AX}(\mathrm{ab} 2893,1: 500)$ (Fig. $2 E-G)$. Primary cultured cerebellar microglia from wild-type mice showed typical resting morphology. When ATM activity was blocked with $1 \mu \mathrm{M}$ KU-60019 for $48 \mathrm{~h}$, however, their morphology took on features more characteristic of the activated state (Fig. $2 \mathrm{H}, \mathrm{I}$ ). The data suggest that in the absence of ATM activity, cerebellar microglia leave the resting state, both in vivo and in vitro.

\section{Loss of ATM induces microglia-mediated neuronal cell damage and apoptosis}

We next investigated the consequences of microglial ATM deficiency on their secretory behavior, in particular the production of substances that could create a neurotoxic environment. We collected conditioned media from primary microglial cultures and applied it to established cultures of embryonic mouse cortical neurons after $14 \mathrm{~d}$ in vitro (DIV 14). After the addition of the conditioned medium the neurons were cultured for an additional $48 \mathrm{~h}$. The conditioned medium from unstimulated cerebellar microglia (MM) led to a small reduction in MAP2-positive cells, but the decrease was not significant (Fig. $3 A$, bottom left, $B-D$ ). By contrast, if the conditioned medium came from microglia that had been treated with the KU-60019 (KM), there was a highly significant amount structural damage to the neurons within $48 \mathrm{~h}$ and the loss of nearly three-quarters of the MAP2-positive cells (Fig. $3 A$, bottom right, $B-D$ ). We noticed that in the KM-treated neuronal culture, the integrity of MAP2 signal along the dendrite was largely compromised, suggesting instability of microtubules and suppressed dendritic transport in those neurons. We quantified the percentage of neurons with discontinuous MAP2 staining, as a marker for damaged neurons. KM significantly increased the percentage of damaged cells in the culture system. To ensure that the effect we observed was not due solely to residual KU60019 left in the KM, we treated the neurons directly with KU60019 in the absence of conditioned medium and found this treatment resulted in neither structural damage nor neuronal death after the same exposure time (Fig. $3 A$, top right, $B-D$ ). While doing no acute harm to the neurons, however, KU-60019 pretreatment sensitized them to a subsequent exposure to KM. These observations are also consistent with our previous hypothesis that the distinct neurological features of $\mathrm{A}-\mathrm{T}$ are not due simply to the cell-autonomous effects of the $\mathrm{Atm}^{-1-}$ genotype of the neurons, but also in no small measure to effects from the resident cerebellar microglia. It is also clear from our data that loss of ATM activity in primary microglia results in their activation in the absence of any exogenous stimulus.

We next measured the density of the presynaptic and postsynaptic markers, synapsin-I and Homer1, in our cultures (Fig. $3 E, F)$. Consistent with our previous findings (Cheng et al., 2018), direct treatment of DIV14 neuronal cultures with $1 \mu \mathrm{M}$ KU-60019 reduced the number of synapsin-I puncta along the MAP2-positive dendrites in the cultures by $\sim$ one-third (Fig. $3 E, G)$. Although conditioned medium from untreated microglia (MM) did not change the number of synapsin-I puncta, KM significantly decreased the density of both synapsin-I and Homer-I puncta (Fig. $3 F, H$ ), indicating a substantial loss of synapses in cultured primary neurons. Neuronal cell loss was also significant in the KM-treated cultures. To determine the nature of this cell loss, we applied the Annexin V/PI staining assay to our cultures and found that the increased cell deaths were predominantly apoptotic in both MM- and KM-treated cultures. The 

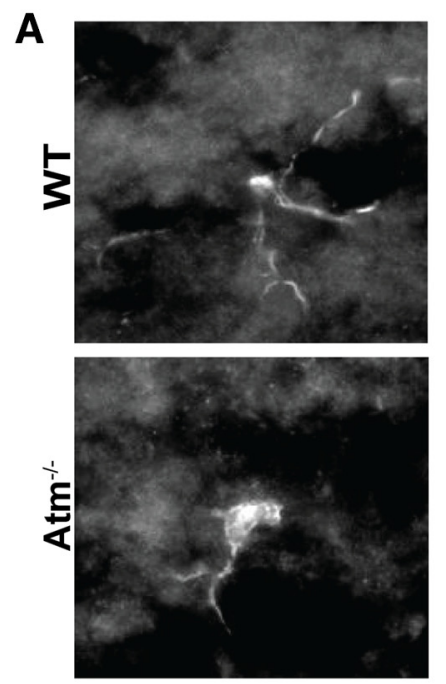

B

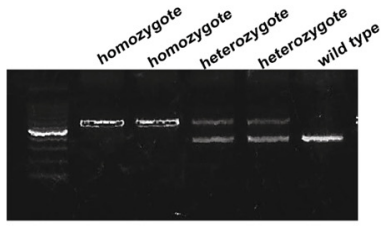

F
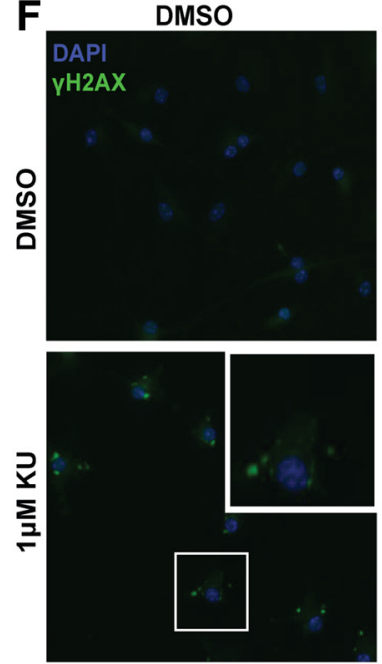

H

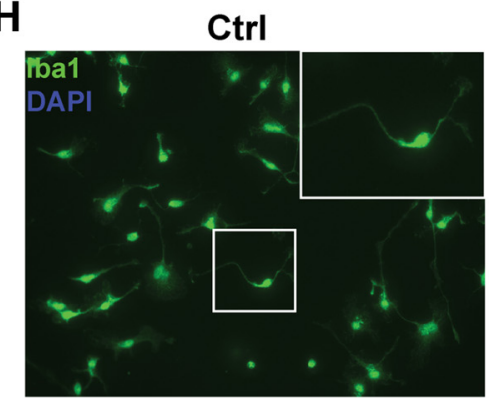

C

E

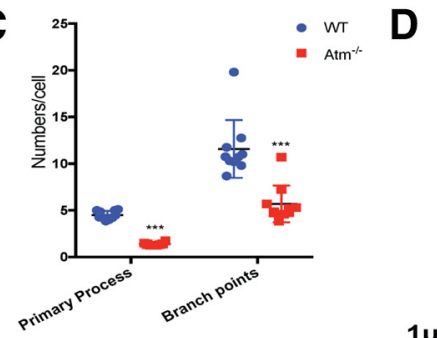

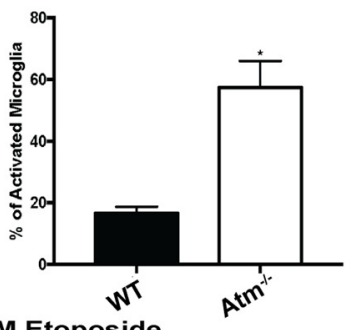

$1 \mu \mathrm{M}$ Etoposide

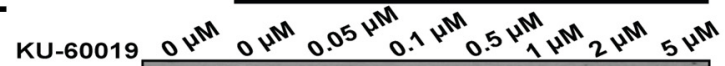

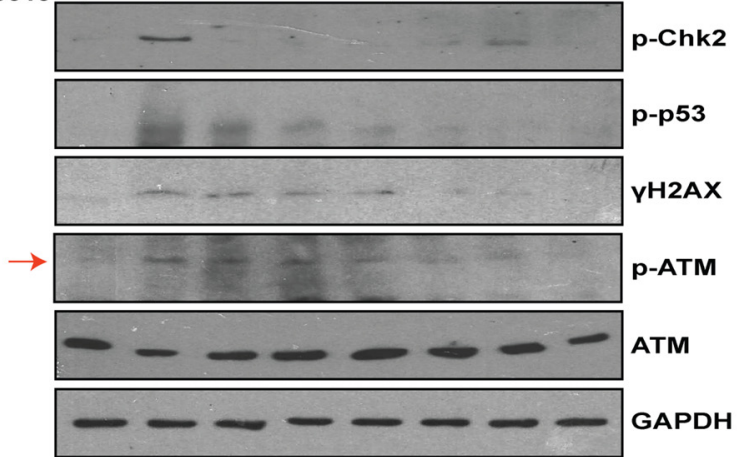

$1 \mu \mathrm{M}$ ETOP
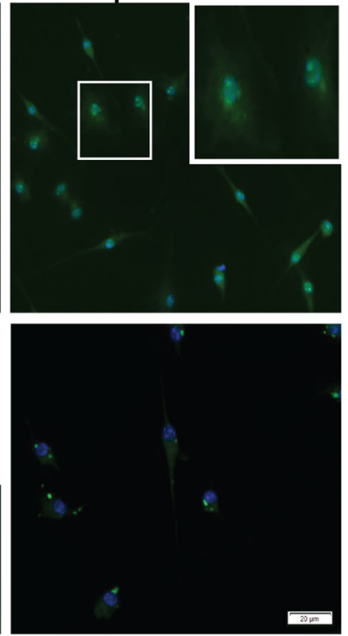

$1 \mu \mathrm{M}$ KU-60019

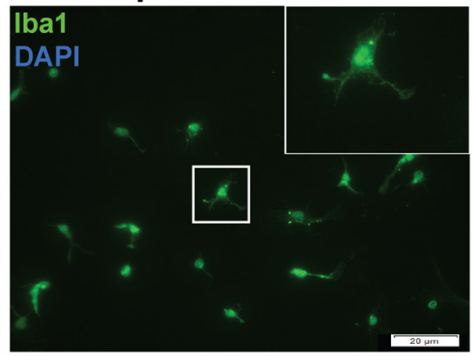

DMSO
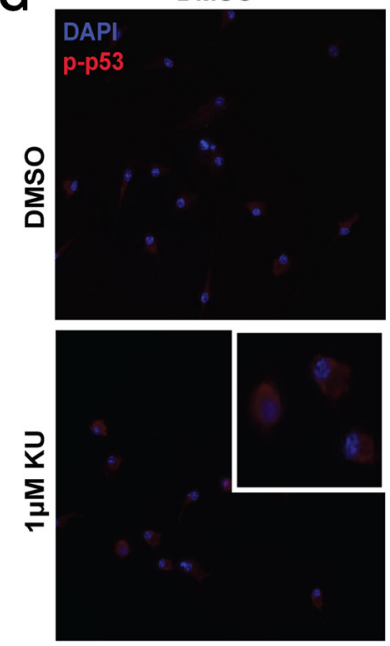

I

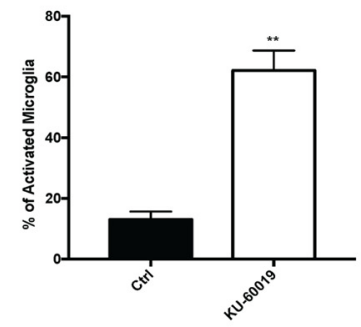

Figure 2. ATM dysfunction results in microglial hyperactivation. $A$, Representative images of microglia, labeled with anti-lba1 antibody, in cerebellum of wild-type and Atm ${ }^{-/-}$animals. $B$, PCR

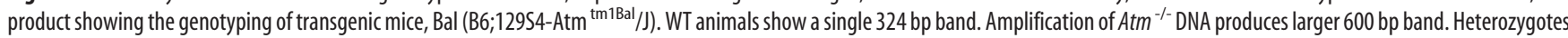
show both bands. C, Quantification of the number of primary processes and branch points of microglia in wild-type (WT) and $\mathrm{Atm}^{-/-}$cerebellar microglia. $n=100-200$ microglia from nine animals for each genotype. Error bars indicate SEM. ${ }^{* * *} p<0.001$ by unpaired $t$ test. $D$, Quantification of percentage of wild-type and $A t m^{-/-}$microglia with an activated phenotype. Error bars indicate SEM. ${ }^{*} p<0.05$, unpaired $t$ test. $\boldsymbol{E}$, Western blots showing the inhibition of ATM kinase activity by different concentrations of KU-60019. ATM kinase activity was measured by the phosphorylation of itself

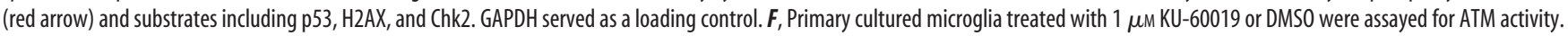
Microglia were labeled with anti- $\gamma \mathrm{H} 2 \mathrm{AX}$ and DAPI (blue). G, Microglia from $1 \mu \mathrm{M} \mathrm{KU-60019}$ or DMSO treated group were labeled with p-p53 (red) antibody and DAPI (blue). $\boldsymbol{H}$, Cultured cerebellar microglia treated with the ATM inhibitor, KU-60019, were immunolabeled with anti-lba1 antibody and counterstained with DAPI (blue). I, Quantification of the percentage of microglia with an activated phenotype after KU-60019 treatment. Error bars indicate SEM. ${ }^{* *} p<0.01$, unpaired $t$ test. 
A MAP2 DAPI
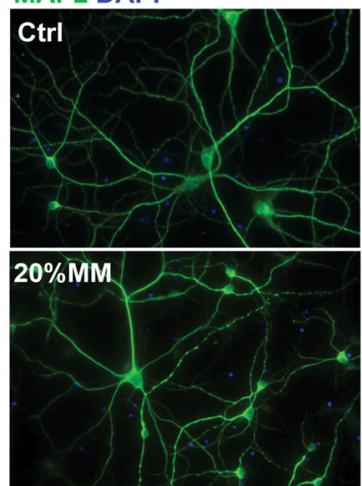

E synapsin I MAP2 DAPI

\section{Ctrl}

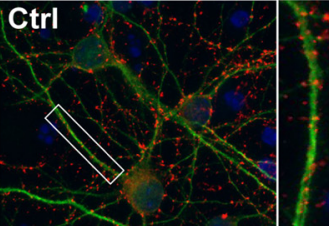

$20 \% \mathrm{MM}$

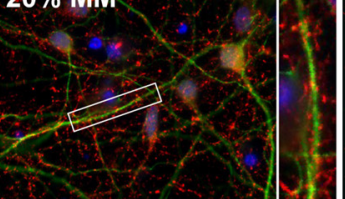

Synapsin 1

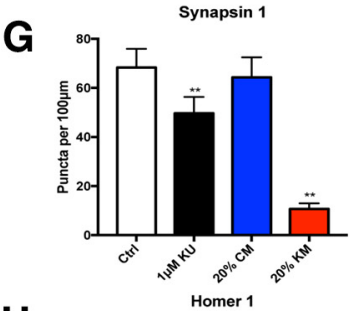

H

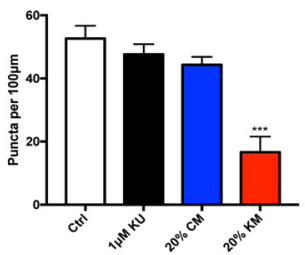

L

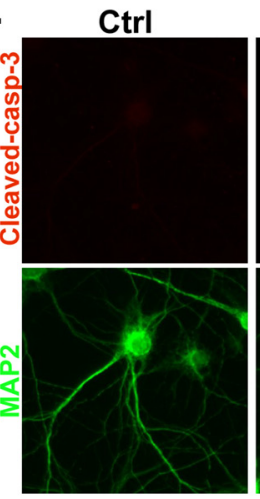

KU-60019

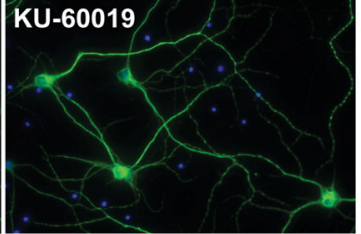

$20 \% \mathrm{KM}$

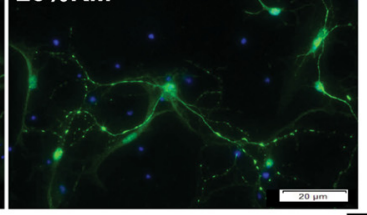

F
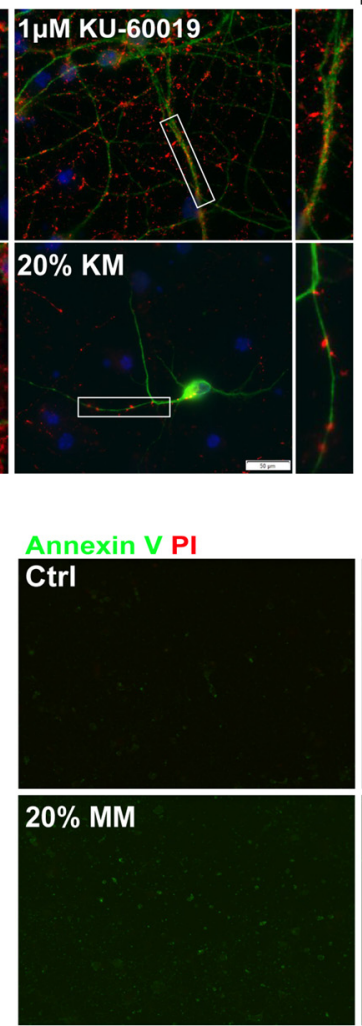

$1 \mu \mathrm{M}$ KU-60019

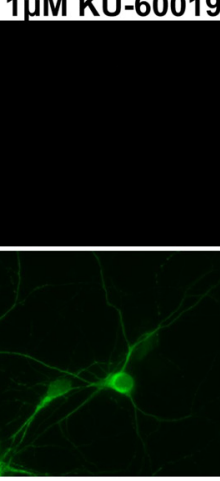

B
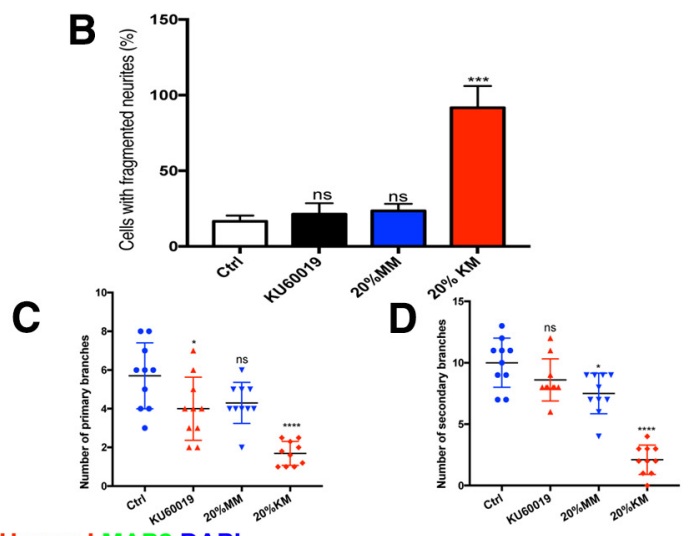

Homer I MAP2 DAPI
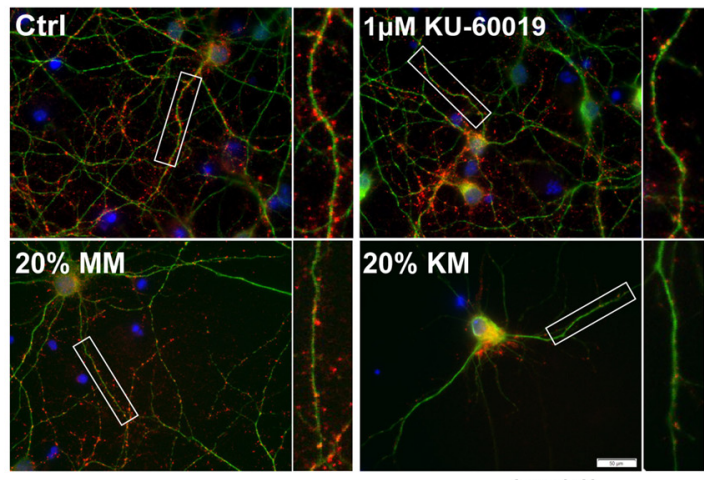

Annexin V
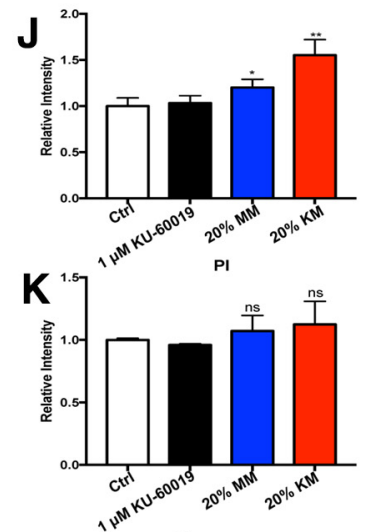

$1 \mu \mathrm{M} \mathrm{KU}-60019$
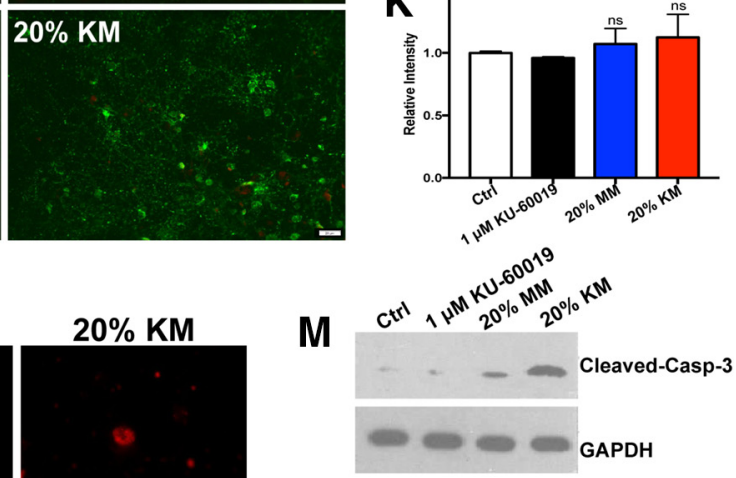

N

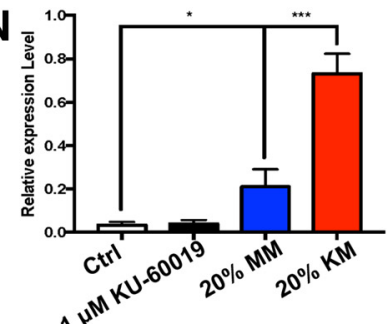

Figure 3. Loss of ATM induces microglia-mediated neuronal cell damage and apoptosis. $A$, Cultured cortical neurons treated (bottom) or untreated (top) with conditioned media collected from microglial culture. KU-60019 was applied to neuronal culture directly (right panels) as a control. Primary neurons were immunolabeled with anti-MAP2. B-D, Quantification of percentage of damaged neuron $(\boldsymbol{B})$ which was indicated by fragmented axon, primary $(\boldsymbol{C})$ and secondary $(\boldsymbol{D})$ branch numbers in the different conditions. Error bars indicate SEM. ns $=$ not significant, ${ }^{*} p<0.05$, ${ }^{* * *} p<0.001$, ${ }^{* * * *} p<0.0001$, unpaired $t$ test. $\boldsymbol{E}, \boldsymbol{F}$, Cultured cortical neurons treated with (bottom) or without (top) conditioned media collected from microglial cultures. Neurons were labeled with (E) anti-synapsin-1 (red) and anti-MAP2 or $(\boldsymbol{F})$ anti-Homer1 (red) and anti-MAP2 antibodies. $\mathbf{G}, \boldsymbol{H}$, Quantification of synapsin-1 puncta $(\boldsymbol{G})$ and Homer-1 puncta $(\boldsymbol{H})$ in cortical neurons. $n=50-60$ neurons from three batches of neuronal cultures. Error bars indicate SEM. ${ }^{* *} p<0.01 ;{ }^{* * *} p<0.001$, unpaired $t$ test. $I$, Annexin V/PI Dead Cell Apoptosis assay shows that Annexin V increased significantly in neuronal cultures treated with KM while the PI signals remained largely unchanged (see text for details). $\boldsymbol{J}, \boldsymbol{K}$, Quantification of Annexin V $(\boldsymbol{J})$ and PI (Figure legend continues.) 
effect from MM was modest, whereas the KM treatment increased neuronal apoptosis by nearly $50 \%$ (Fig. $3 I, J$ ). The PI signal remained largely unchanged suggesting little contribution from necrotic forms of cell loss (Fig. $3 I, K$ ). In keeping with the Annexin- $\mathrm{V}$ results, KM robustly elevated the levels of cleavedcaspase 3 in the cultures (Fig. $3 L-N$ ). We also found a modest, but still significant, increase after MM treatment. Thus, ATMdeficient microglia condition their medium with neurotoxic factors that promote synaptic loss and neuronal apoptosis.

\section{ATM deficiency primes microglia for a proinflammatory response}

As the resident macrophages of the CNS, microglia rapidly respond to damage and injury. Once activated, they move quickly to clear cellular debris and mount an inflammatory response through endocrine and paracrine signals (Hanisch, 2002). To investigate the role of ATM in this process, we immunostained primary cultures of cerebellar microglia to monitor the nuclear translocation of p65, an indicator of the activation of NF- $\kappa \mathrm{B}$ pathway. After exposure to $1 \mu \mathrm{M} \mathrm{KU}-60019$ for $48 \mathrm{~h}$, p65 moved to the nucleus in nearly half the cells (Fig. $4 A, B$ ). We assessed additional aspects of the drug-induced inflammatory response with RT-PCR. We found a significant increase in message levels of genes for the proinflammatory cytokines IL- $1 \beta$, TNF- $\alpha$, IL-12, IL-6, and CCL2 in the presence of KU-60019 (Fig. 4C). In these same cultures, KU-60019 treatment reduced the message levels of anti-inflammatory cytokine genes such as Arg1 and Ym1 (Fig. 4D).

Next, we investigated whether it was the release of proinflammatory cytokines from the microglia that causes the neurotoxicity of KM toward neurons. As IL- $1 \beta$ was the cytokine with the most dramatic increase in mRNA level (of the cytokines we tested), we asked whether its protein levels in microglial cell lysates were also elevated after KU-60019 and found that they were (Fig. $4 E$ ). The increased IL-1 $\beta$ protein was also externalized. KU60019 treated microglia released a significantly greater amount of IL- $1 \beta$ into their medium than untreated controls (Fig. $4 E-G$ ). To better mimic the interactions between microglia and neurons as they occur in the brain, rather than using conditioned medium, we established a neuron-microglia coculture system. KU-60019 applied directly to neuronal culture in the absence of microglia had virtually no effect (Fig. $3 A-D$ ). By contrast, we observed severe neuronal structural damage (fragmented axons) and cell loss when KU-60019 was added to the neuron-microglial coculture system (Fig. $4 H$, top row, $I-K$ ). Both the KM effect and the coculture toxicity were dependent on IL- $1 \beta$. If we pretreated the mixed cultures with $10 \mu \mathrm{g} / \mathrm{ml}$ of an IL-1 receptor antagonist, IL-1RA, for $4 \mathrm{~h}$ (Arend and Gabay, 2000; Thornton et al., 2006), we found that the neurotoxicity was significantly blunted (Fig. $4 H-K)$. Significantly, the effect of the antagonist appeared to be directly on the neuronal response to the KM. The morphological changes and nuclear localization of p65 after KU-60019 treatment were largely unchanged in the presence of IL1-RA (Fig. $4 \mathrm{Hi}, \mathrm{Hii}$ ). Thus, ATM deficiency triggers a proinflammatory response in cultured microglia that results in the production and

\section{$\leftarrow$}

(Figure legend continued.) $\quad(\boldsymbol{K})$ measured by ImageJ. $n=10$ views for each three batches of neuronal cultures. Error bars indicateSEM. ns $=$ not significant, ${ }^{*} p<0.05$; ${ }^{* *} p<0.01$, unpaired $t$ test. $L$, Images of individual neurons stained with anti-cleaved caspase 3 (red), anti-MAP2 and DAPI (blue) for nuclei. $\boldsymbol{M}$, Western blots of cleaved caspase 3 in cell lysates of DIV 14 neurons treated with conditioned media. GAPDH served as a loading control. $N$, Quantification of the blots shown in $M . n=$ $3-4$ independent neuronal cultures. Error bars indicate SEM. ${ }^{*} p<0.05$; ${ }^{* * *} p<0.001$. secretion of IL- $1 \beta$ and other cytokines, which are major drivers of the KM-induced neuronal cell death.

\section{Loss of ATM induces accumulation of cytosolic DNA}

ATM is a critical component of the cellular DNA damage response (Maréchal and Zou, 2013), and in its absence the balance between DNA damage and repair is lost. The result is an increase in unrepaired damage. We reasoned that one possible signal tying ATM deficiency to cytokine production would be the accumulation of fragments of unrepaired genomic DNA that ended up moving to the cytoplasm (Ahn et al., 2014). In this ectopic location, the DNA fragments would be perceived as an invading virus and trigger an antiviral immune response. These were exactly the genes that were upregulated in cerebellar microglia with age (Fig. 1 ). We performed nuclear/cytoplasmic fractionation of microglial cell lysates followed by DNA precipitation and separation on an ethidium gel. The stained gel revealed a dramatic increase in DNA within the cytoplasmic fraction of KU-60019-treated cells (Fig. $5 A, D$ ) as measured by Qubit Assays. We verified this observation in situ by immunostaining of primary cultured microglia (Fig. 5B) using antibodies against single-strand DNA (ssDNA) and double-strand DNA (dsDNA). Inhibition of ATM kinase led to a significant increase in the intensity of immunostaining of both antibodies in the microglial cytoplasm. Quantification of the immunostaining intensity confirmed this visual impression (Fig. 5C). We further validated the presence of cytoplasmic DNA by showing that ATM inhibition increased the signal of the TUNEL reaction in the cytoplasm (Fig. $5 E-G$ ). As a final in vitro confirmation, we performed fluorescence activated cell sorting (FACS) of normal and KU-60019 treated microglia stained with ssDNA and dsDNA antibodies (Fig. 5H). We next looked for homologous responses in vivo and found them. In adult $\mathrm{Atm}^{-1-}$ mice, cerebellar microglia showed elevated cytoplasmic signals for both ssDNA and dsDNA (Fig. 5I).

As part of the innate immune system, microglial cells would be highly likely to have a vigorous antiviral defense program. ATM, however, is a nearly ubiquitous protein. Its absence should compromise DNA damage repair in any cell type, theoretically leading to the production of cytoplasmic DNA. To test this, we treated cultured HEK293FT cells with KU-60019 and found that they too accumulated DNA in their cytoplasm (Fig. 6A,B). Further, as suggested by the HEK293FT results, cytosolic DNA was not confined exclusively to the microglia in vivo. ATM-deficient neurons were also affected. For example, $\mathrm{Atm}^{-/-}$cerebellar Purkinje cells accumulated both ssDNA and dsDNA in their cytoplasm (Fig. 6C). We next cultured mouse embryonic fibroblasts from $\mathrm{Atm}^{-/-}$mice and found that they too showed a substantially increased presence of cytosolic DNA (Fig. $6 D-G$ ), a finding that we verified with FACS analysis of these cells (Fig. $6 D-F$ ). These experiments also offered a clue to the source of the cytoplasmic DNA. Specifically, we found a negative correlation between ATM protein level and the intensity of the cytosolic DNA signal (Fig. $6 D)$. We extended these findings to human cells by culturing fibroblasts from A-T patients and healthy controls. FACS analysis showed a distinct negative correlation between the level of ATM protein and cytosolic DNA (Fig. 6H). Replotting these results revealed a clear increase of both single strand and double strand DNA in the fibroblasts from A-T patients (Fig. 6I). Notably, we found the cytoplasmic staining for both ssDNA and dsDNA was frequently punctate (Fig. 6J, white arrows). 

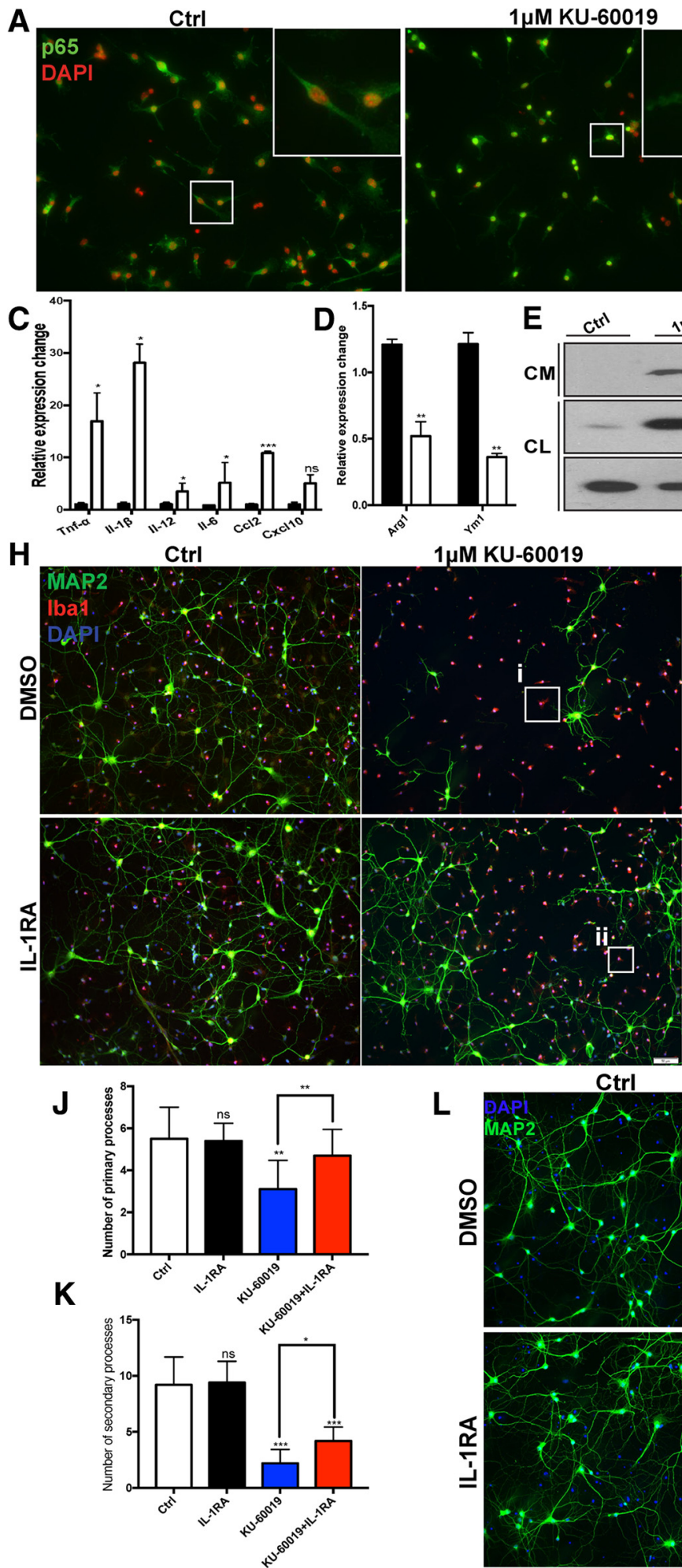

$1 \mu \mathrm{M} \mathrm{KU}-60019$

E
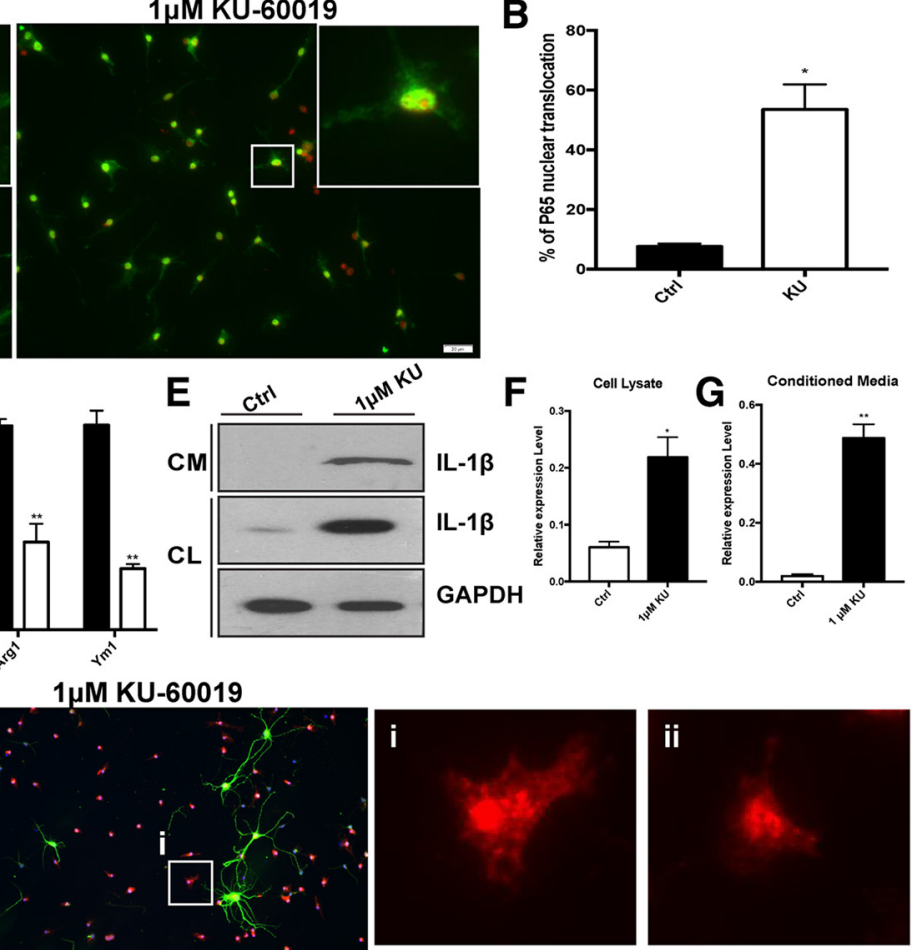

I

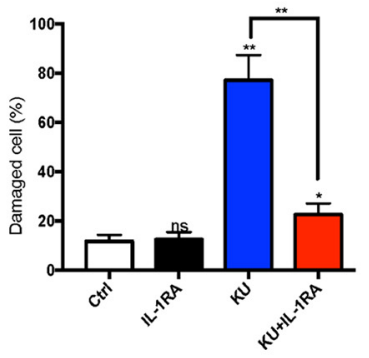

KM
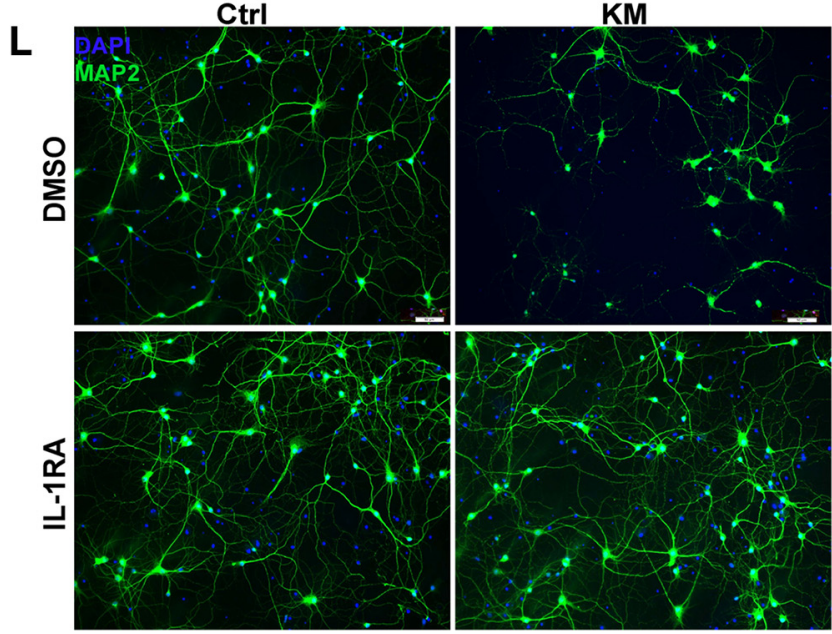

Figure 4. ATM deficiency potentiates the microglial inflammatory response. $A$, Primary cultured cerebellar microglia, treated with (right) or without KU-60019. Cells were immunoassayed with antibody against p65 plus DAPI for nuclei respectively. $\boldsymbol{B}$, Percentage of microglia with nuclear translocation of $\mathrm{p} 65 . n=100$ microglia from three batches of microglial cultures. Error bars indicate SEM. ${ }^{*} p<0.05$. C, qRT-PCR for the relative levels of Inf- $\alpha,\|1-1 \beta\| I-12,, I I-6, C \mathrm{Cl}$, and $\mathrm{CXCl10}$ to Gapdh mRNA in primary microglia cultured in normal growth medium or in the presence of $1 \mu \mathrm{m}$ KU-60019. Error bars indicate SEM. $n=4,{ }^{*} p<0.05,{ }^{* * *} p<0.001$. D, qRT-PCR was used to determine the levels of $Y m 1$ and Arg 1 relative to Gapdh mRNA in primary microglia cultured in normal growth medium or in the presence of $1 \mu \mathrm{m} \mathrm{KU-60019}$. Error bars indicate SEM. $n=4,{ }^{* *} p<0.01$. E, Western blots of IL-1 $\beta$ in cell lysates of microglia (CL) or their culture (conditioned) medium (CM). $\boldsymbol{F}, \mathbf{G}$, Quantification of the blots shown in E. $n=3-4$ independent microglial cultures. Error bars indicate SEM. ${ }^{*} p<0.05,{ }^{* *} p<0.01 . \boldsymbol{H}$, Neuron/microglia coculture system treated with or without KU-60019 and IL-1RA. Neurons and microglia were stained with MAP2 and Iba1 (red), respectively, plus DAPI (blue). Active microglia found in the white boxes are enlarged and shown in insets $\boldsymbol{H i}$ and $\boldsymbol{H i i} . \boldsymbol{I}-\boldsymbol{K}$, Quantification of neuronal damage indicated by fragmented axon $(\boldsymbol{I})$, primary branches $(\boldsymbol{I})$ and secondary branches $(\boldsymbol{K})$ of neurons in the indicated conditions. Error bars indicate SEM. ns $=$ not significant, ${ }^{*} p<0.05 ;{ }^{* *} p<0.01 ;{ }^{* * *} p<0.001$, by unpaired $t$ test. $L$, Cultured cortical neurons were pretreated with IL-1RA before KM was applied to the culture. Neurons were labeled with anti-MAP2 plus DAPI. 
A
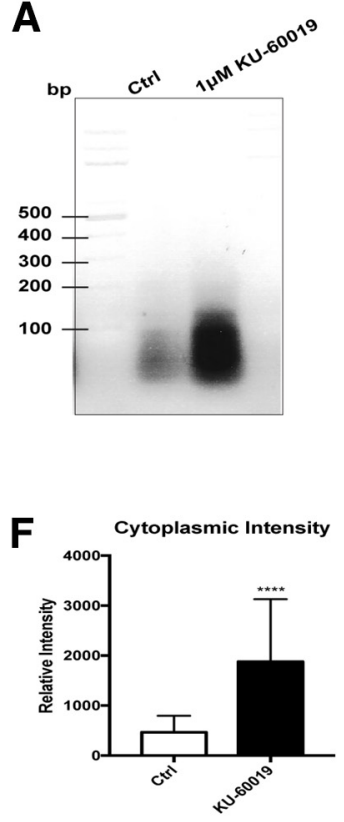

G

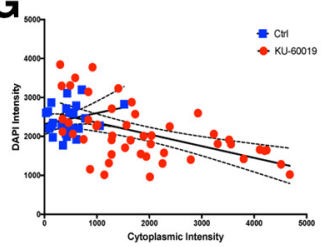

B

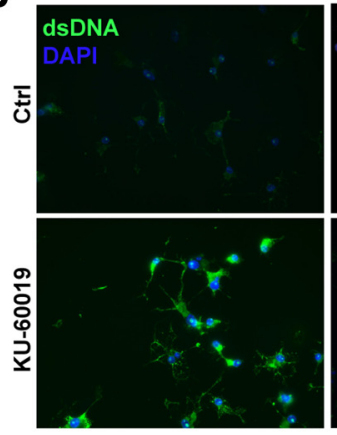

H

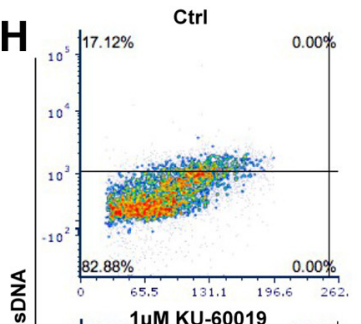

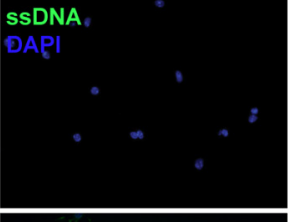

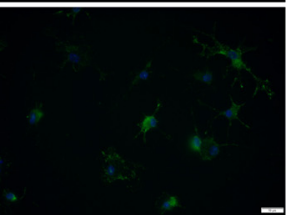

C

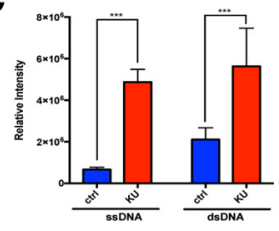

D

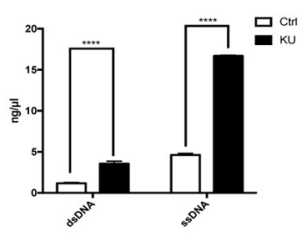

E
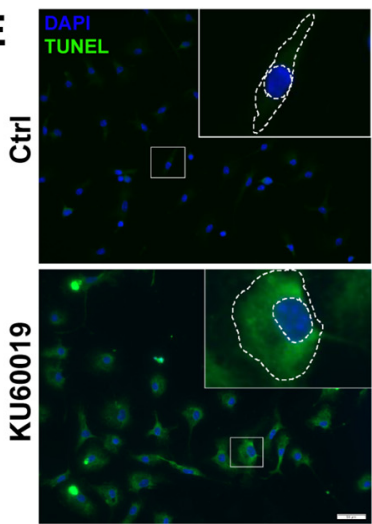
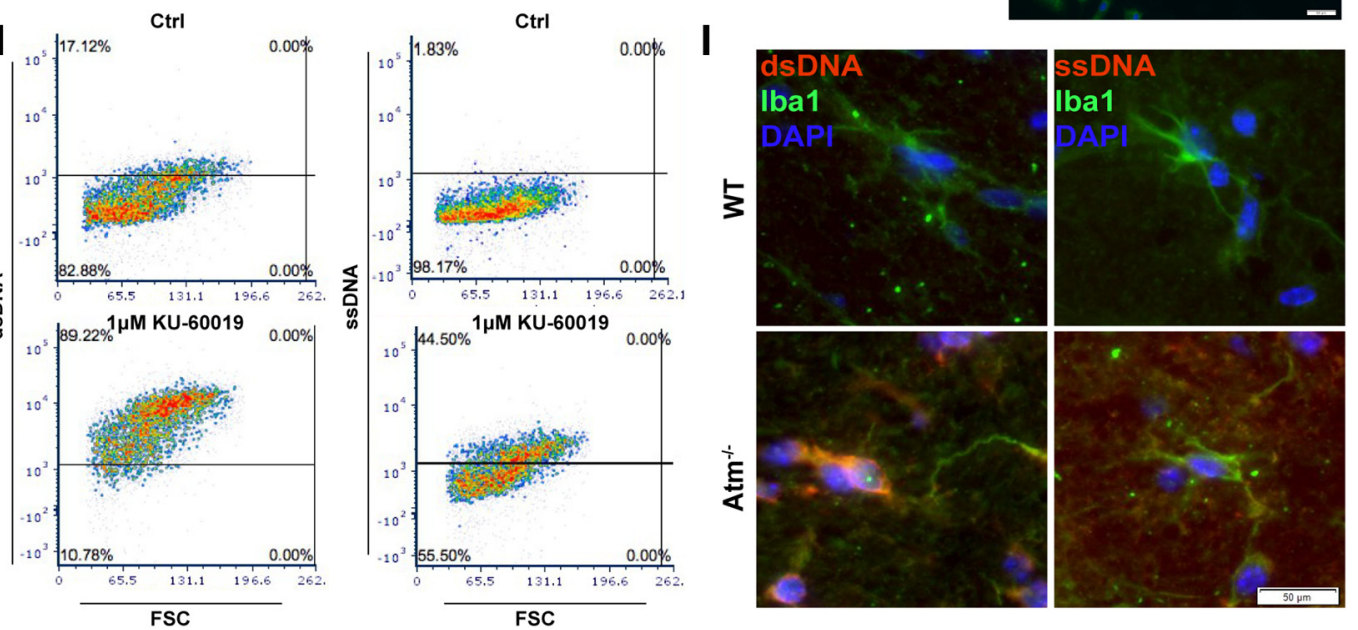

Figure 5. Loss of ATM induces the accumulation of cytosolic DNA. A, Agarose gel analysis of cytoplasmic extracts from primary microglia treated with (lane 1) or without (lane 2) KU-60019. B Primary cultures microglia treated with KU-60019 and stained with anti-dsDNA (left) or anti-ssDNA (right), shown in green, plus DAPI (blue). C, Quantification of the signal intensity of individual microglia using ImageJ for both ssDNA and dsDNA. $n=100$ microglia from three different batches of culture. Error bars indicate SEM. ${ }^{* * *} p<0.001$. D, Quantification of the cytoplasmic DNA with Qubit Assays. $n=3 \sim 4$ independent microglial cultures. Error bars indicate SEM. ${ }^{* * *} p<0.0001$.E, In situ detection of fragmented DNA using the TUNEL reaction in microglia treated with (bottom) or without (top) KU-60019. F, Quantification of cytoplasmic TUNEL intensity shown in Figure $4 E . n=3-4$ independent cultures. Error bars indicate SEM. ${ }^{* * * *} p<0.0001$. G, Linear regression curve of cytoplasmic DNA and nuclear DNA measured by TUNEL intensity and DAPI intensity respectively. The slopes of the control and KU-60019 treated groups were $0.28\left(r^{2}=0.27\right)$ and $-0.31\left(r^{2}=\right.$ 0.05) respectively. $\boldsymbol{H}$, Flow cytometry (FACS) analysis of microglia treated with KU-60019. Microglia were labeled with anti-dsDNA or anti-ssDNA. In total, 100,000 cells were measured. $I$, Brain sections from 1-month-old wild-type and $\mathrm{Atm}^{-/-}$mice were stained with ssDNA (right) and dsDNA (left) antibodies, shown in red. Microglia were labeled with anti-lba 1 antibody and DAPI for nucleus (blue).

\section{STING mediates the proinflammatory response of}

ATM-deficient microglia

Cytosolic DNA has long been recognized as an immune stimulus that forms an important part of the cellular defense against viral infection (Paludan and Bowie, 2013). In the response to cellular infection with viruses or other pathogens, a key protein responsible for detection of cytosolic DNA is STING (stimulator of interferon genes- Burdette and Vance, 2013). STING is normally found in an inactive state, localized on the ER. Upon activation by phosphorylation, it leaves the ER and moves to the perinuclear region (Barber, 2015; Curran et al., 2016; Mathur et al., 2017; Cheng et al., 2018). We hypothesized that after loss of ATM function, fragments of genomic DNA would be leaked to the cytoplasm where they would activate a proinflammatory response by signaling through STING. We tested this hypothesis and showed that KU-60019 treatment of microglia led to significant changes in both STING phosphorylation (Fig. 7A,C,D), and its cellular localization (Fig. $7 A, B$ ), even while the total levels of STING protein remained unchanged (Fig. 7A). TBK1 and $\mathrm{p} 65$ phosphorylation also increased (Fig. $7 E-G$ ), a situation suggesting that the NF- $\kappa$ B pathway was activated. The STING-dependent nature of these changes was shown by reducing the levels of STING with shRNA before KU-60019 administration. This treatment blunted the impact of ATM inhibition on the phosphorylation of p65 (Fig. $8 D$, top). Finally, we turned to pharmacology and a STING specific inhibitor, CCCP (Prantner et al., 2012; Kwon et al., 2017). Blocking STING activity significantly reduced both the production and secretion of proinflammatory cytokines after ATM inhibition (Fig. 8A-C). We then demonstrated the dependence of the response on the presence of DNA and STING in three ways. First, we used shRNA to knockdown Trexl, the DNase that normally degrades DNA fragments in the cytoplasm of healthy cells (Fig. $8 D$, bottom). Blocking Trex1 activity has previously been shown to induce a STING-dependent proinflammatory response (Yang et al., 2007) and in our system reducing Trex1 also resulted in a significant activation of the p65 component of NF- $\kappa \mathrm{B}$ pathway. As expected, cotreatment with STING shRNA blunted the effect of ATM inhibitor in elevating the phospho-p65 signals (Fig. $8 D$, top). Second, using CCCP to reduce STING activation, we blocked the production of proinflammatory cytokines after ATM inhibition (Fig. $8 A-C$ ). Finally, inducing additional DNA damage, by treating the cells with the topoisomerase inhibitor etoposide (ETOP), further increased the levels of cytosolic DNA as well as the levels of cytokine production (Fig. $8 E-H$ ).

We note that cell type variation in the response to DNA damage also illustrates the dependence of our findings on the actions 

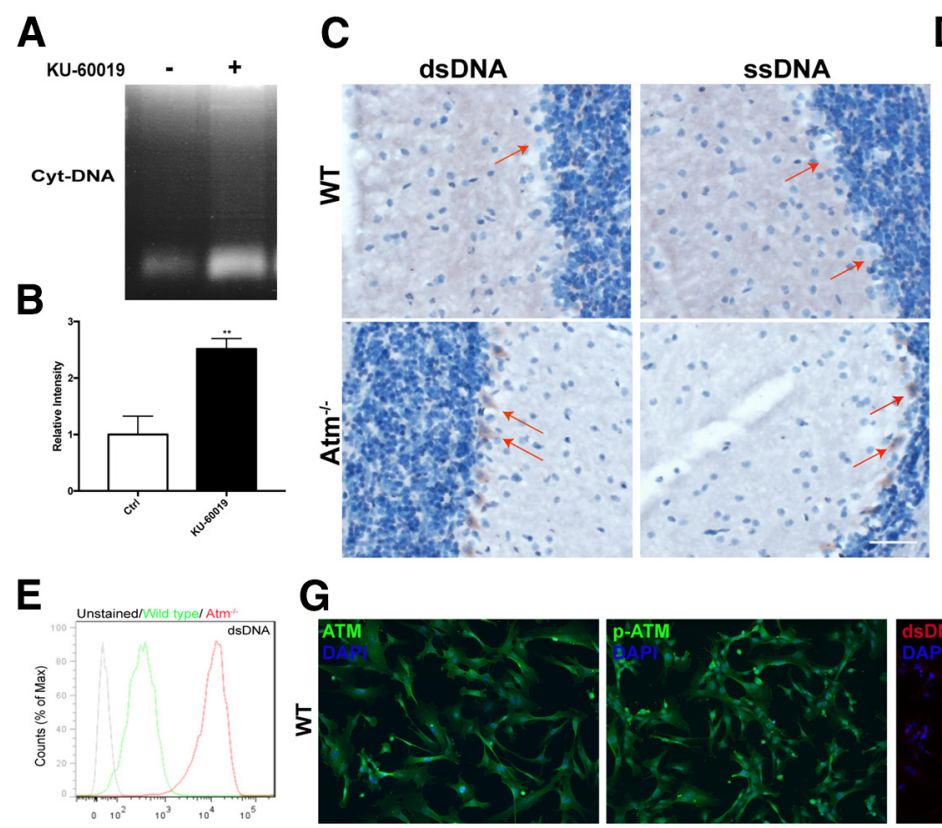

G
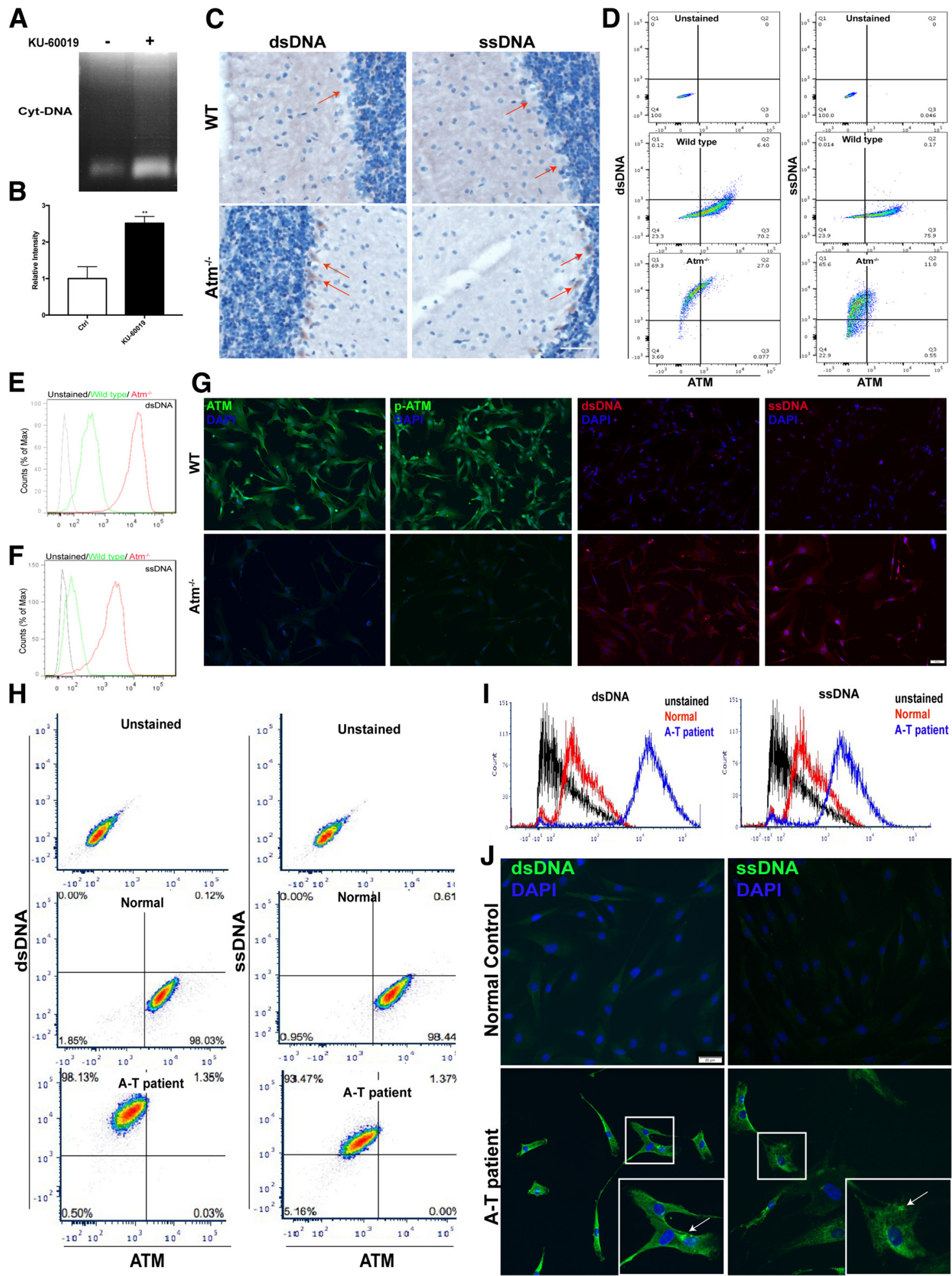

Figure 6. Loss of ATM induces accumulation of cytosolic DNA. A, Agarose gel analysis of cytoplasmic extracts from HEK293FT cells treated (lane 1) or untreated (lane 2) with KU-60019. $\boldsymbol{B}$, Quantification of the gel shown in A. $n=3-4$ independent cultures. Error bars indicate SEM. ${ }^{* *} p<0.01$. C, Representative images of Purkinje cells, labeled with, dsDNA (left) and ssDNA (right) antibodies respectively. D, FACS analysis of dsDNA (left) and ssDNA (right) in mouse embryonic fibroblasts cultured from wild-type and $\mathrm{Atm}^{-1}$. Cells were costained with antibodies against DNA $(y$-axis) and ATM (x-axis). $\boldsymbol{E}, \boldsymbol{F}$, Histogram of the FACS data shown in $\boldsymbol{D}$. G, Immunostaining with antibodies against ATM, p-ATM, dsDNA, and ssDNA in mouse embryonic fibroblasts cultured from wild-type (top) and ATM knock-out animals (bottom). $\boldsymbol{H}$, FACS analysis of dsDNA (left) and ssDNA (right) in fibroblasts from human A-T patients and controls. Cells were costained with antibodies against DNA (y-axis) and ATM ( $x$-axis). $\boldsymbol{I}$, Histogram of the FACS data shown in $\boldsymbol{H}$.J, Human fibroblasts from controls and A-T patients were labeled with anti-dsDNA (left) and anti-ssDNA (right) plus DAPI (blue). 
A
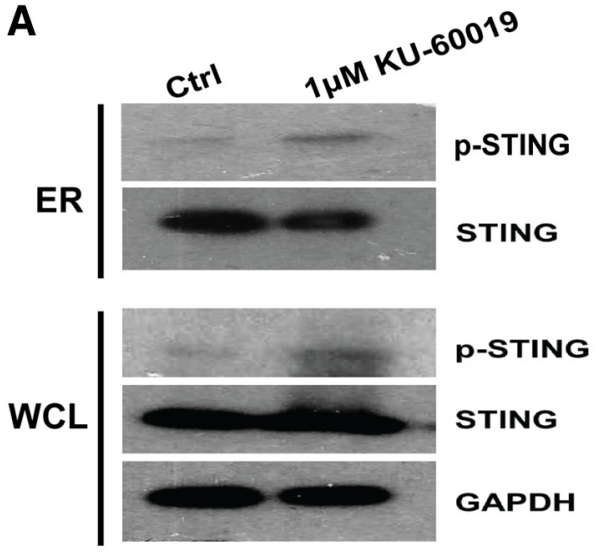

B

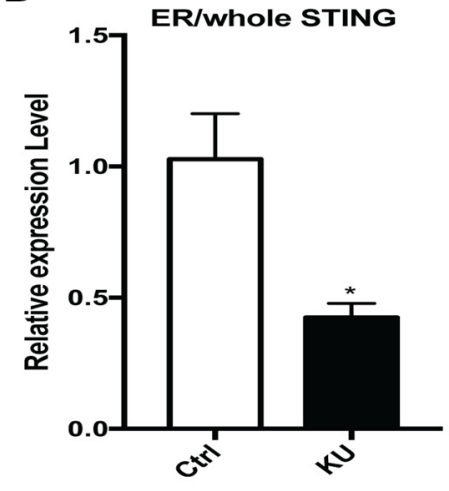

C

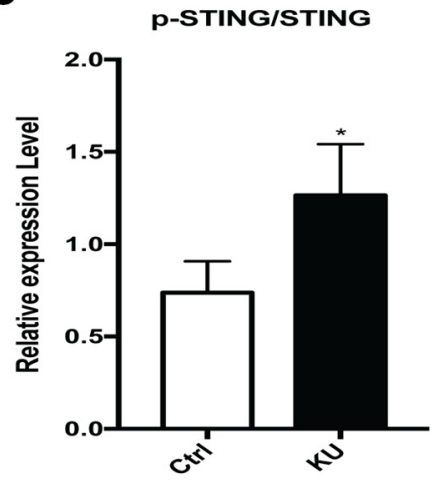

D

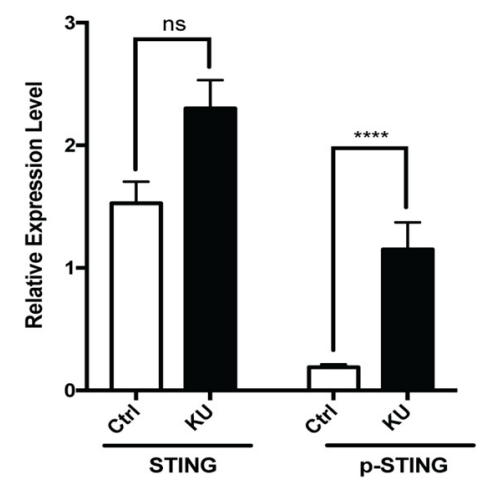

E

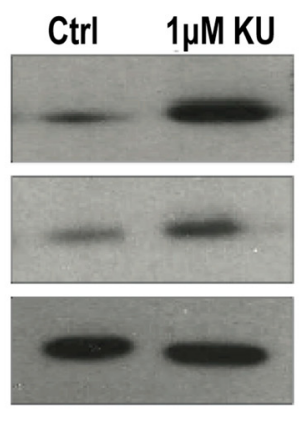

F

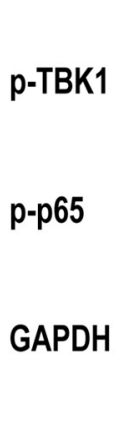

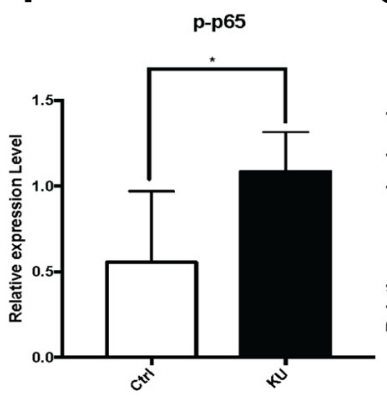

G

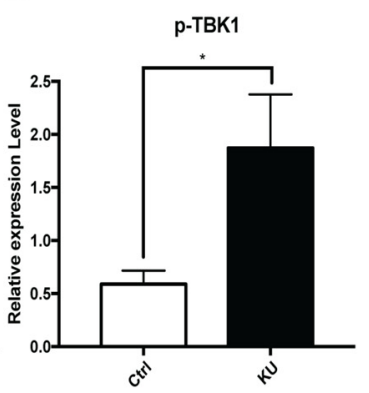

Figure 7. The cytoplasmic DNA sensor STING is activated in ATM-deficient microglia. $A$, Western blots of STING and p-STING. GAPDH served as a loading control in both whole-cell lysates (bottom) and ER fractions (top) of microglia cultures treated with or without KU-60019. B-D, Quantification of the blots shown in $A . n=3-4$ independent microglial cultures were used for analysis. Error bars indicate SEM. ns $=$ not significant, ${ }^{*} p<0.05 ;{ }^{* * * *} p<0.0001 . E$, Western blots of p-p65 and p-TBK1 in microglia treated with or without KU-60019. F, G, Quantification of the blots shown in $E . n=3-4$ independent microglial cultures. Error bars indicate SEM. ${ }^{*} p<0.05$.

of STING. HEK293 cells accumulate cytoplasmic DNA when treated with KU-60019. Since these cells do not normally express STING, however, they activate neither TBK1 nor p65 (Fig. 8I-L). Nonetheless, when sister cultures were transfected with a STINGexpressing plasmid, KU-60019 treatment led to the activation of both TBK1 and p65 (Fig. 8I-L). FACS analysis confirmed these findings (Fig. 8M). The exogenous STING was phosphorylated under these conditions and translocated to the perinuclear region (Fig. $8 N$ ), thus responding as would endogenous STING to the elevated levels of cytoplasmic DNA (Fig. $8 \mathrm{~N}, \mathrm{O}$ ). Interestingly, KU-60019 treatment also led to the redistribution of STING from a more diffuse presence in the cell body to an aggregated, more punctate pattern found in the perinuclear region (Fig. 8Ni,Nii). In the aggregate, we interpret these results to imply that STING plays a central role in triggering the inflammatory response in ATM-deficient microglia and other cell types.

\section{Loss of ATM induces AIM2-inflammasome activity}

We returned to the question of how STING could induce not only the expression of the IL- $1 \beta$ mRNA and its translation into pro-IL- $1 \beta$, but also its proteolytic processing by caspase- 1 , a step that is required for the production of all active interleukin-1 family cytokines (Martinon et al., 2002; Afonina et al., 2015). Caspase- 1 is found as one of the critical components of an active inflammasome. (Kostura et al., 1989; Thornberry et al., 1992; Creagh et al., 2003). Two major subtypes of inflammasomes are recognized in microglial cells. Both of them contain procaspase-1 and ASC (apoptosis-associated speck like protein). Their differences lie in whether they use the NLRP (nucleotide- binding domain, leucine-rich-containing family, pyrin domaincontaining), a type of NOD-like receptor (nucleotide-binding oligomerization domain-like receptors) (Franchi et al., 2009), or AIM2 (absent in melanoma 2) (Lugrin and Martinon, 2018) in their structure. We exposed primary cultures of microglia to KU60019 and recorded a dramatic increase in immunostaining intensity of both ASC and Caspase-1 (Fig. 9A-D). In addition, both proteins changed their subcellular localization after ATM inhibition, assuming a punctate distribution consistent with the formation of inflammasomes. Western blots of parallel cultures were also consistent with this finding (Fig. 9E,F). After KU-60019 treatment, ASC oligomers increased, demonstrating the assembling of the inflammasome (Fig. 9E), whereas increased cleavedcaspase-1 demonstrated the activation of the inflammasome (Fig. $9 F$ ). We have already shown that microglia accumulate DNA species in the cytoplasm with ATM deficiency. Cytoplasmic DNA first induce the activation of NF- $\kappa \mathrm{B}$ pathway leading to the production of pro-IL-1 $\beta$. We then would like to investigate whether cytosolic DNA also regulated the processing of pro-IL- $1 \beta$ to IL$1 \beta$. AIM2 can specifically sense the cytosolic DNA and participating in the activation of inflammasome (Rathinam et al., 2010). AIM2 immunocytochemistry showed an increase in intensity as well as an altered cellular distribution pattern that colocalized with two other inflammasome components: ASC and caspase-1 (Fig. 9G). To verify the physical nature of this association, we immunoprecipitated AIM2 from primary microglial lysates and showed that ASC precipitated with it. The reverse coimmunoprecipitation using ASC antibody to pull down AIM2 was also successful. In both cases the interaction between ASC and AIM2 was 

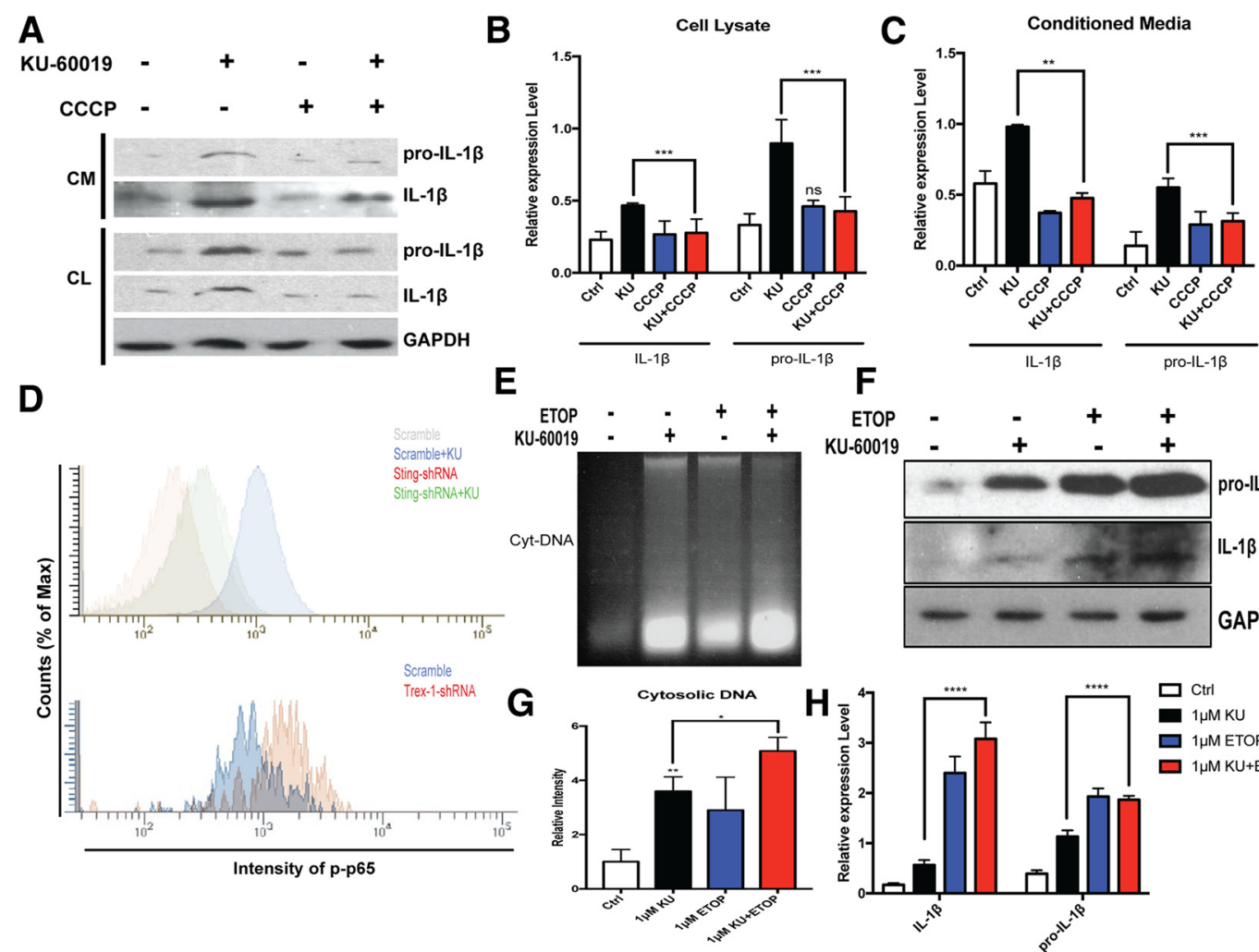

\section{$\mathbf{F}$}
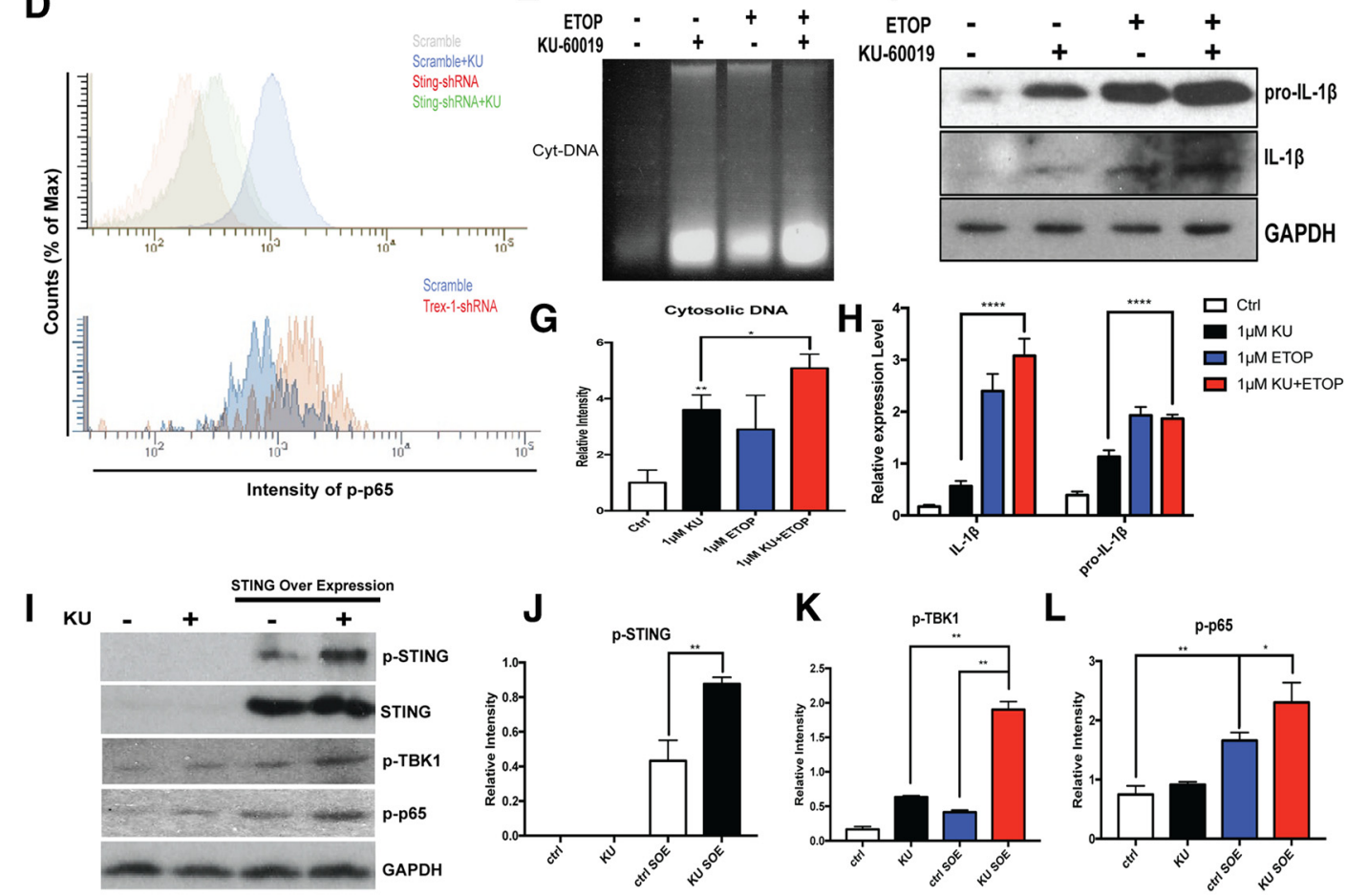

K
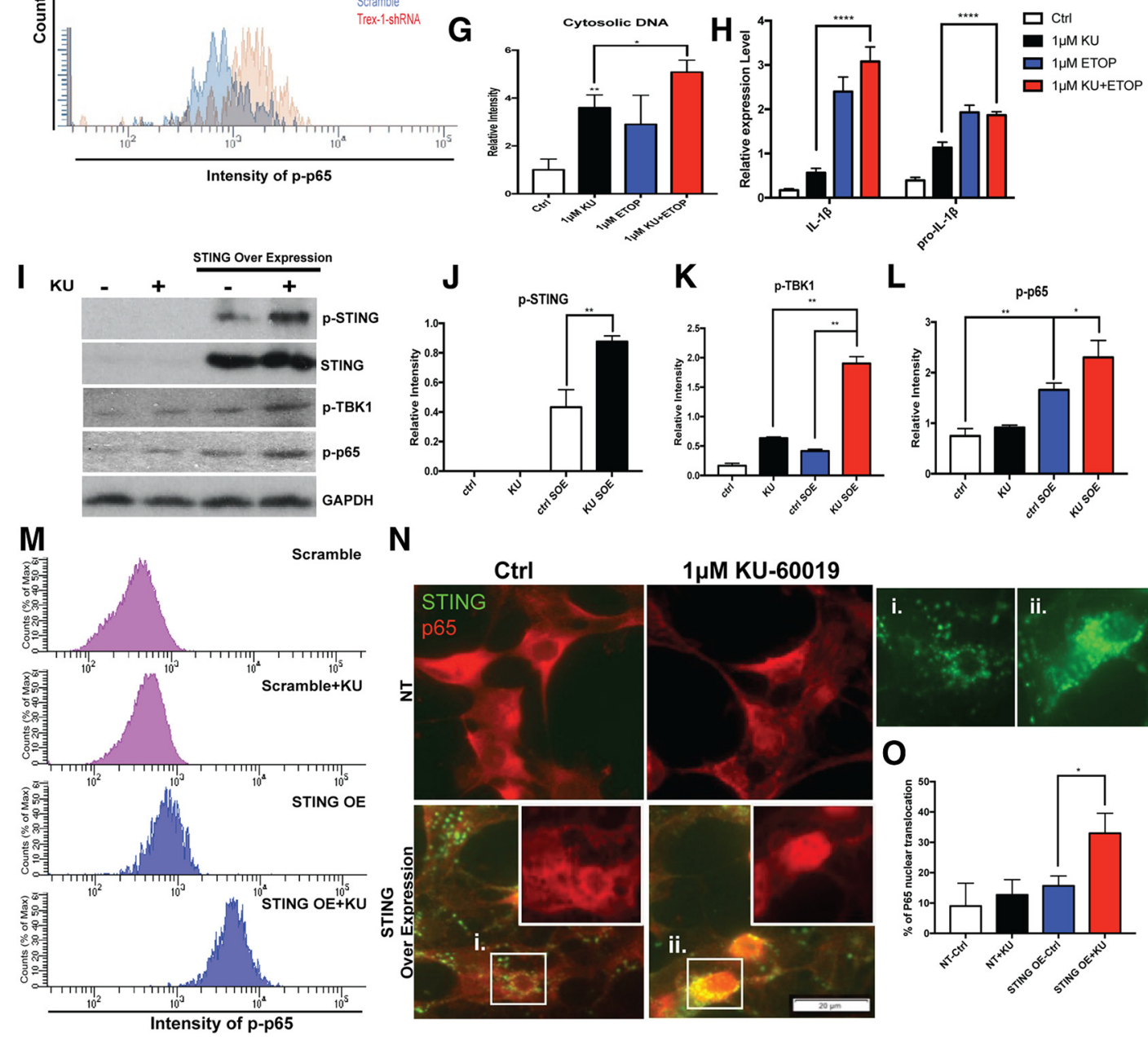

N

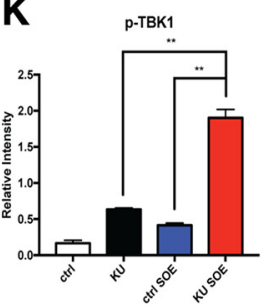

L

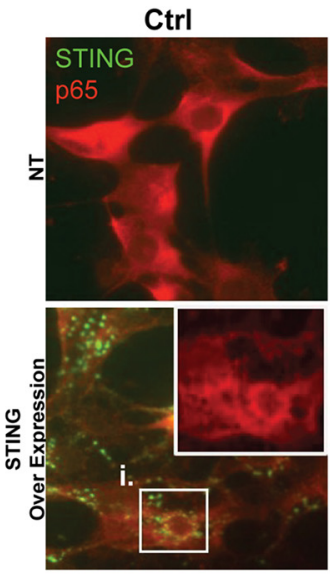

\section{$1 \mu \mathrm{M}$ KU-60019}

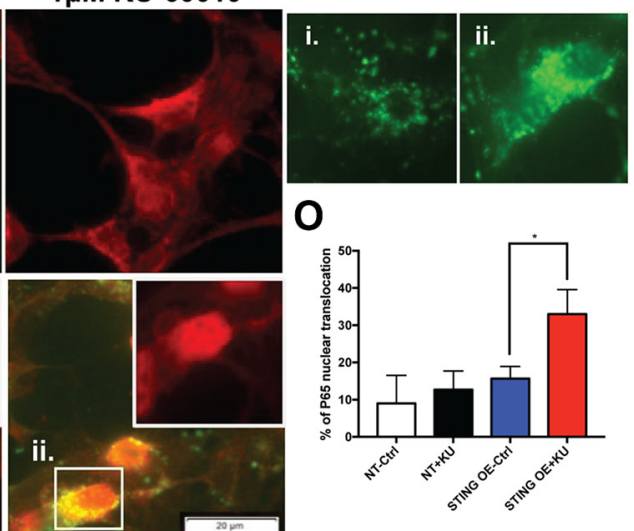

Figure 8. STING mediates cytosolic DNA-induced antivirus response in ATM-deficient microglia. $A$, Western blots of pro-IL-1 $\beta$ and IL-1 $\beta$ in both whole-cell lysate and conditioned media from microglia cultures. $\boldsymbol{B}, \boldsymbol{C}$, Quantification of the blots shown in $\boldsymbol{A}$. Relative expression of pro-IL-1 $\beta$ and IL-1 $\beta$ in cell lysate $(\boldsymbol{B})$ and conditioned media $(\boldsymbol{C})$ are measured, respectively. $n=3-4$ independent microglial cultures. Error bars indicate SEM. ns $=$ not significant, ${ }^{*} p<0.05 ;{ }^{* * *} p<0.001$. D, Flow cytometry analysis of p-p65 intensity in microglia. $n=3-4$ independent microglial cultures. $\boldsymbol{E}$, Agarose gel analysis of cytoplasmic extracts of microglia cells from control cultures (lane 1) or cultures treated with KU-60019 (lane 2), etoposide (ETOP) (lane 3) or both (lane 4). $\boldsymbol{F}$, Western blots of pro-IL-1 $\beta$ and IL-1 $\beta$ from microglia cultures treated as indicated. G, Quantification of the gel shown in $E . n=3-4$ independent cultures. Error bars indicate SEM. ${ }^{*} p<0.05 ;{ }^{* *} p<$ 0.01. $\boldsymbol{H}$, Quantification of the blot shown in $\boldsymbol{F} . n=3-4$ independent cultures. Error bars indicate SEM. ${ }^{* * *} p<0.001$; ${ }^{* * * *} p<0.0001$. I, Western blots of STING, p-STING, p-p65, and p-TBK1 in HEK 293FT cells. GAPDH served as a loading control. J-L, Quantification of the blots shown in $I$ with four different conditions. SOE, STING overexpression. $n=3-4$ independent cultures. Error bars indicate SEM. ${ }^{*} p<0.05,{ }^{* *} p<0.01 . M$, FACS analysis of $p$-p 65 intensity in HEK293FT cells following different treatments as indicated. $\boldsymbol{N}$, HEK293FT cells were stained with $p 65$ (red). Green shows the transfected mtagGFP-labeled STING. STING pattern in HEK293FT cells with or without the KU-60019 treatment are shown individually in Ni and Nii. O, Percentage of the HEK293FT cells shown in $\boldsymbol{N}$ with nuclear translocation of p65. $n=3-4$ independent cell cultures. Error bars indicate SEM. ${ }^{*} p<0.05$. 
A

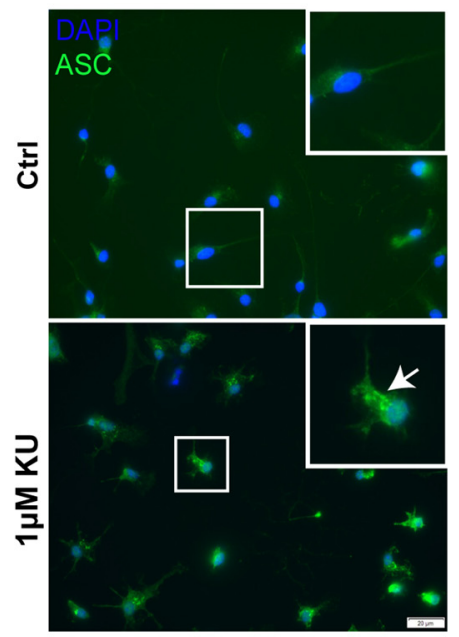

G

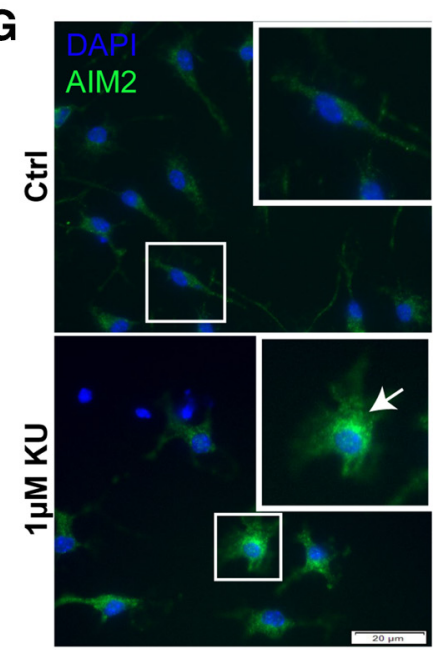

B

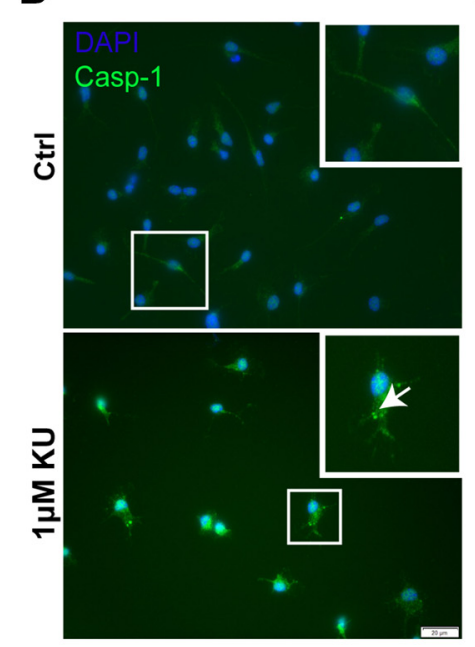

H

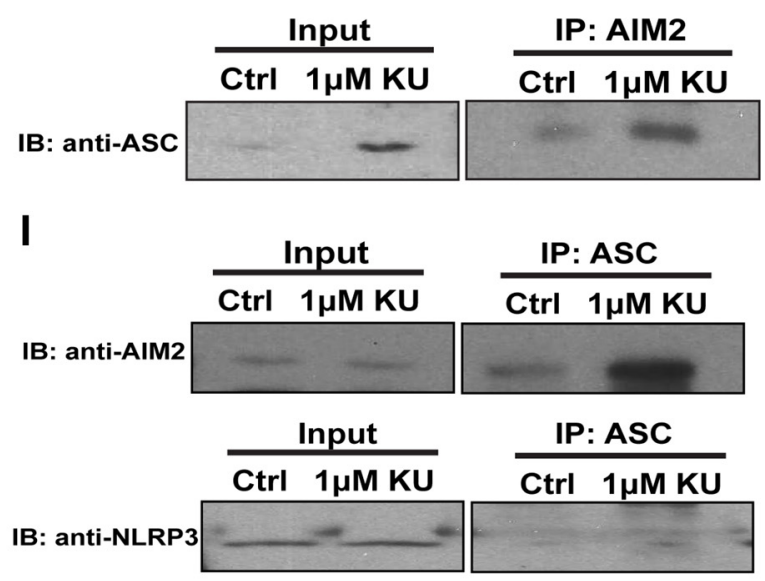

C

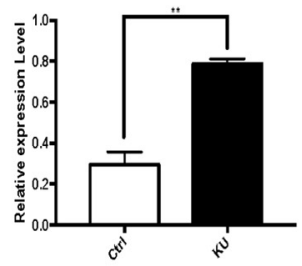

E

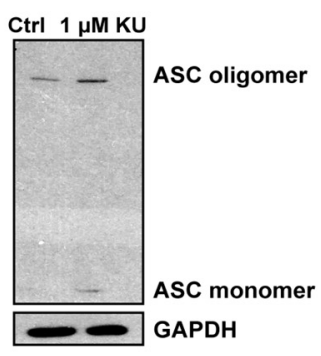

D

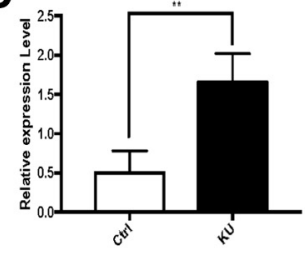

F

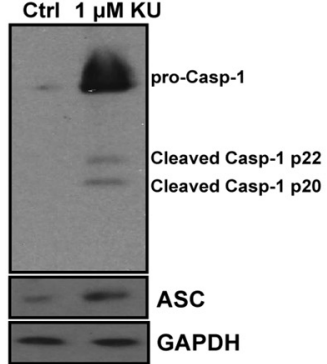

J

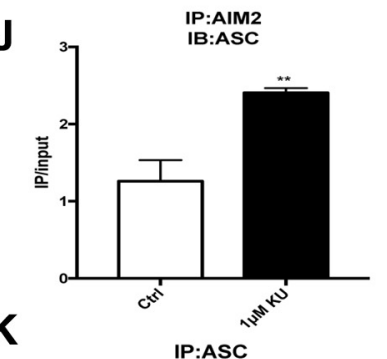

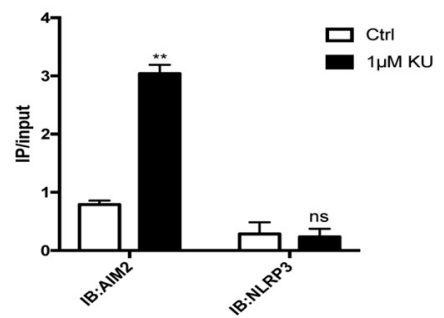

Figure 9. Loss of ATM induces AIM2-containing inflammasome activity. $\boldsymbol{A}$, Primary cerebellar microglia, from control or KU-60019-treated group, were labeled with anti-ASC and DAPI (blue). $\boldsymbol{B}$, Primary cerebellar microglia from controls or the KU-60019-treated group were labeled with anti-caspase 1 and DAPI (blue). C, D, Quantification of the signal intensity of individual microglia using ImageJ for ASC $(\boldsymbol{A})$ and Caspase $1(\boldsymbol{B}) . n=3-4$ independent cultures. Error bars indicate SEM. ${ }^{* *} p<0.01$. $\boldsymbol{E}$, ASC Western blots showing oligomerization following KU-60019 treatment. GAPDH was used as a loading control. $\boldsymbol{F}$, Western blots of caspase 1 in cell lysates from microglia cultured with or without KU-60019. GAPDH was used as a loading control. G, Immunostaining of AIM2 and DAPI (blue) in cultured microglia. $\boldsymbol{H}$, Immunoprecipitation with AIM2 antibody of cell lysates from microglia treated with KU-60019. Interaction between AIM2 and ASC was analyzed by Western blot using antibody against ASC as indicated. II Immunoprecipitation with ASC antibody of cell lysates from microglia treated with KU-60019. Interaction between proteins was analyzed by Western blot using antibodies against AIM2 or NLRP3 as indicated. $\boldsymbol{J}$, Quantification of blots shown in $\boldsymbol{H} . n=3-4$ independent microglial cultures. Error bars indicate SEM. ${ }^{* *} p<0.01$. $\boldsymbol{K}$, Quantification of blots shown in $I . n=3-4$ independent microglial cultures. Error bars indicate SEM. ns $=$ not significant, ${ }^{* *} p<0.01$.

stronger in KU-60019 treated microglia (Fig. 9H-K). In contrast to these results, NLRP3 was not pulled down by the ASC subunit (Fig. 9I, bottom, $K$ ), indicating the proteolytic processing of proIL- $1 \beta$ in ATM-deficient condition is primarily if not exclusively mediated by AIM2-containing inflammasomes.

\section{Discussion}

The present findings highlight the significance of microglianeuron interactions in the progression of the neurodegenerative symptoms of A-T and show how defective DNA damage repair can lead to an inflammatory response that has lethal consequences for neurons. Our data show that in $\mathrm{Atm}^{-/-}$mice, cerebellar microglia are hyperactivated and in this activated state, they condition their medium with strong neurotoxic agents.

Persons with A-T are viewed as immune deficient, and in the years immediately following the discovery of the ATM gene, it seemed that this disease symptom was largely explained by compromised $\mathrm{V}(\mathrm{D}) \mathrm{J}$ recombination-a DNA damage and repair process that requires ATM-and the resulting failure in the development of the acquired immune response. This focus on acquired immunity was logical because a major cause of morbidity and mortality in A-T patients is respiratory bacterial infections due at least in part to T-and B-cell deficiencies. However, the full spectrum of A-T immune deficiencies has proven to be broader than this, and the mechanisms linking immune deficiencies to the neurological symptoms are not well understood. Previous findings have shown that in both human A-T and its mouse models, anti-inflammatory betamethasone treatments blunt the severity of the neurological symptoms (Menotta et al., 2012; Zannolli et al., 2012; Giardino et al., 2013). These findings have been extended to mice; NSAIDs blocked the appearance of some cell biological symptoms of $\mathrm{Atm}^{-1-}$ mice: the activation of the brain 
microglia and the development of ectopic cell cycle events in Purkinje neurons (Hui et al., 2018).

Activated microglial cells produce a complex mixture of cytokines and chemokines, many of which could damage neurons. While different active components may be involved, the evidence suggests that IL- $1 \beta$ is a major contributor to the neurotoxic properties of this mixture (Hui and Herrup, 2015). We add to that evidence here by showing that much of the damage induced by $\mathrm{KM}$ in our neuronal cultures can be prevented by pretreatment with IL-1RA, an IL- $1 \beta$ receptor antagonist. We also show that the IL- $1 \beta$ produced in our system is from cleaved from its pro-IL- $1 \beta$ precursor through the actions of the caspase activity of the AIM2containing inflammasome. This result highlights the presence of an alternative pathway for generating IL- $1 \beta$ that is independent of the NLRP3 inflammasome. This is a significant finding as this NLRP3-containing inflammasome complex is impaired in the absence of ATM (Erttmann et al., 2016), but is highly active in other neurodegenerative diseases, such as Alzheimer's disease (Akiyama et al., 2000).

Although our data provide a strong basis for proposing a role for the innate immune system in the A-T neurodegenerative phenotype, monocytes, macrophages and microglia in the brain do not undergo $\mathrm{V}(\mathrm{D}) \mathrm{J}$ recombination or any other known DNA rearrangement during their development. The question arises, therefore, what is it about the lack of ATM activity that triggers this innate immune response? The answer appears to lie in the inappropriate activation of the antiviral response, which is specifically upregulated in cerebellar microglia as shown by our in silico analysis. This suggests that the cerebellar microglia are more sensitive and primed to initiate an immune stimulus. In the absence of ATM activity, achieved either with pharmacological inhibition of the kinase or by genetic means in ATM knock-out cells, we observe the accumulation of both single strand and double strand DNA in the cytoplasm. This cytosolic DNA then serves as a potent danger signal that activates a classic antiviral response via the DNA sensor, STING. Activated STING subsequently initiates a robust proinflammatory response via the NF- $\kappa$ B pathway, resulting in the production of a variety of cytokines. These secreted products of inflammation are neurotoxic (alone or in combination) and we show that in vitro they are sufficient to kill large numbers of neurons in established cultures of embryonic mouse cortex.

We note that, by itself, the presence of cytoplasmic DNA is not sufficient to trigger a neurotoxic response. Neurons for example, can accumulate cytoplasmic DNA yet not respond in any detectable fashion. This highlights the critical role for STING in the microglial cell reaction. Neurons do not produce STING; without it they would appear to be unable to respond to the presence of cytoplasmic DNA and thus unable to activate their NF- $\kappa$ B pathway. Whether this ectopic DNA triggers other responses in the cell is unknown, but our findings should be considered in light of the observation of activity-induced DNA damage observed in neurons previously (Suberbielle et al., 2013). As their DNA damage could well result in the appearance of DNA in the cytoplasm of treated cell, and our preliminary data suggest that this is true (data not shown). We expect therefore that the in vivo stimuli in that previous study would also result in enhanced levels of cytoplasmic DNA.

One additional question that we have addressed in our study is the exact origin of the cytosolic DNA. As shown by our ethidium gels, the size of the DNA fragments is small making it likely that, in the absence of ATM-dependent DNA repair, persistent DNA damage accumulates in the nuclear genome. Since the DNA damage repair machinery is compromised, small fragments of the double helix might separate from the genome and find their way to the cytoplasm. This scenario receives support from our findings that inducing DNA damage alone, even in the presence of normal ATM activity, can itself induce accumulation of cytosolic DNA and trigger inflammation in an ATM-dependent manner, as has been reported by others (Li et al., 2001; McCool and Miyamoto, 2012). Blocking the ATM-dependent DNA damage repair machinery by inhibiting ATM kinase function, however, makes a bad situation worse and leads to further accumulation of DNA in the cytoplasm. In addition to compromised repair, a second potential source of the cytoplasmic DNA fragments is enhanced DNA damage, particularly that induced by oxidative damage. ATM has a known anti-oxidant function (Ito et al., 2004; Semlitsch et al., 2011) and can act as a redox sensor (Guo et al., 2010). In the absence of ATM, therefore, reactive oxygen species would be expected to increase, leading to specific forms of DNA damage in the nucleus and small DNA fragments that would once again find their way to the cytoplasm. Both the reduced repair and increased damage scenarios presume that the source of the cytosolic DNA is the cell's own nucleus, an explanation that also accounts for the negative correlation between the levels of cytoplasmic DNA measured by TUNEL intensity and the amount of nuclear DNA measured by DAPI intensity (Fig. 5G). A final potential origin of the cytoplasmic DNA is the mitochondria. Mitochondrial dysfunction is a known feature of cells from $\mathrm{Atm}^{-1-}$ mice, worms, and cultured cells (Valentin-Vega et al., 2012). It is proposed that this is due to the function of ATM as a regulator of mitochondrial autophagy (mitophagy) (Fang and Bohr, 2017). With mitophagy compromised, fragments of the mitochondrial genome might also contribute to the accumulated DNA in the cytoplasm. Any of these possible sources could contribute in whole or in part to the observed accumulation of cytoplasmic DNA. Whatever their source is, their increased presence occurs in response to decreased ATM activity. In microglial cells, where STING is present, the result is the triggering of the antiviral inflammatory response with pathological consequences for neurons.

Overall, our results confirm a significant role for the innate immune system in the process of neurodegeneration in $\mathrm{A}-\mathrm{T}$ and link this directly to the DNA damage response functions of the ATM kinase. In the absence of ATM function, impaired DNA damage repair causes the accumulation of cytoplasmic DNA and the subsequent activation of the antiviral defense system via the DNA sensor STING. This leads to an increase in the levels of pro-IL-1 $\beta$ and its proteolytic processing by AIM2-inflammasome. Together, these processes create an inflammatory environment with strong neurotoxicity. We propose that, beyond their clear implications for the neurological symptoms in A-T, the present findings suggest the involvement of microglial DNA damage as a trigger for neuroinflammation during the etiology of other neurodegenerative conditions.

\section{References}

Afonina IS, Müller C, Martin SJ, Beyaert R (2015) Proteolytic processing of interleukin-1 family cytokines: variations on a common theme. Immunity 42:991-1004.

Ahn J, Ruiz P, Barber GN (2014) Intrinsic self-DNA triggers inflammatory disease dependent on STING. J Immunol 193:4634-4642.

Akiyama H, Barger S, Barnum S, Bradt B, Bauer J, Cole GM, Cooper NR, Eikelenboom P, Emmerling M, Fiebich BL, Finch CE, Frautschy S, Griffin WS, Hampel H, Hull M, Landreth G, Lue L, Mrak R, Mackenzie IR, McGeer PL, et al. (2000) Inflammation and Alzheimer's disease. Neurobiol Aging 21:383-421. 
Arend WP, Gabay C (2000) Physiologic role of interleukin-1 receptor antagonist. Arthritis Res 2:245-248.

Bagley J, Singh G, Iacomini J (2007) Regulation of oxidative stress responses by ataxia-telangiectasia mutated is required for $\mathrm{T}$ cell proliferation. J Immunol 178:4757-4763.

Bakkenist CJ, Kastan MB (2003) DNA damage activates ATM through intermolecular autophosphorylation and dimer dissociation. Nature 421: 499-506.

Banin S, Moyal L, Shieh S, Taya Y, Anderson CW, Chessa L, Smorodinsky NI, Prives C, Reiss Y, Shiloh Y, Ziv Y (1998) Enhanced phosphorylation of p53 by ATM in response to DNA damage. Science 281:1674-1677.

Barber GN (2015) STING: infection, inflammation and cancer. Nat Rev Immunol 15:760-770.

Boche D, Perry VH, Nicoll JA (2013) Activation patterns of microglia and their identification in the human brain. Neuropathol Appl Neurobiol 39:3-18.

Bosotti R, Isacchi A, Sonnhammer EL (2000) FAT: a novel domain in PIKrelated kinases. Trends Biochem Sci 25:225-227.

Bredemeyer AL, Sharma GG, Huang CY, Helmink BA, Walker LM, Khor KC, Nuskey B, Sullivan KE, Pandita TK, Bassing CH, Sleckman BP (2006) ATM stabilizes DNA double-strand-break complexes during V(D)J recombination. Nature 442:466-470.

Bredemeyer AL, Huang CY, Walker LM, Bassing CH, Sleckman BP (2008) Aberrant $\mathrm{V}(\mathrm{D}) \mathrm{J}$ recombination in ataxia telangiectasia mutated-deficient lymphocytes is dependent on nonhomologous DNA end joining. J Immunol 181:2620-2625.

Burdette DL, Vance RE (2013) STING and the innate immune response to nucleic acids in the cytosol. Nat Immunol 14:19-26.

Chaudhary MW, Al-Baradie RS (2014) Ataxia-telangiectasia: future prospects. Appl Clin Genet 7:159-167.

Chen P, Peng C, Luff J, Spring K, Watters D, Bottle S, Furuya S, Lavin MF (2003) Oxidative stress is responsible for deficient survival and dendritogenesis in purkinje neurons from ataxia-telangiectasia mutated mutant mice. J Neurosci 23:11453-11460.

Cheng A, Zhao T, Tse KH, Chow HM, Cui Y, Jiang L, Du S, Loy MMT, Herrup K (2018) ATM and ATR play complementary roles in the behavior of excitatory and inhibitory vesicle populations. Proc Natl Acad Sci U S A 115:E292-E301.

Chessa L, Micheli R, Molinaro A (2016) Focusing new ataxia telangiectasia therapeutic approaches. J Rare Dis Diagn Ther 2:12-20.

Combs CK, Johnson DE, Cannady SB, Lehman TM, Landreth GE (1999) Identification of microglial signal transduction pathways mediating a neurotoxic response to amyloidogenic fragments of beta-amyloid and prion proteins. J Neurosci 19:928-939.

Crawford TO, Mandir AS, Lefton-Greif MA, Goodman SN, Goodman BK, Sengul H, Lederman HM (2000) Quantitative neurologic assessment of ataxia-telangiectasia. Neurology 54:1505-1509.

Crawshaw AA, Robertson NP (2017) The role of TSPO PET in assessing neuroinflammation. J Neurol 264:1825-1827.

Creagh EM, Conroy H, Martin SJ (2003) Caspase-activation pathways in apoptosis and immunity. Immunol Rev 193:10-21.

Curran E, Chen X, Corrales L, Kline DE, Dubensky TW Jr, Duttagupta P, Kortylewski M, Kline J (2016) STING pathway activation stimulates potent immunity against acute myeloid leukemia. Cell Rep 15:2357-2366.

Driessen GJ, Ijspeert H, Weemaes CM, Haraldsson Á, Trip M, Warris A, van der Flier M, Wulffraat N, Verhagen MM, Taylor MA, van Zelm MC, van Dongen JJ, van Deuren M, van der Burg M (2013) Antibody deficiency in patients with ataxia telangiectasia is caused by disturbed B- and T-cell homeostasis and reduced immune repertoire diversity. J Allergy Clin Immunol 131:1367-1375.e9.

Erttmann SF, Härtlova A, Sloniecka M, Raffi FA, Hosseinzadeh A, Edgren T, Rofougaran R, Resch U, Fällman M, Ek T, Gekara NO (2016) Loss of the DNA damage repair kinase ATM impairs inflammasome-dependent anti-bacterial innate immunity. Immunity 45:106-118.

Evans DT, Serra-Moreno R, Singh RK, Guatelli JC (2010) BST-2/tetherin: a new component of the innate immune response to enveloped viruses. Trends Microbiol 18:388-396.

Fang EF, Bohr VA (2017) NAD(+): the convergence of DNA repair and mitophagy. Autophagy 13:442-443.

Farr AK, Shalev B, Crawford TO, Lederman HM, Winkelstein JA, Repka MX (2002) Ocular manifestations of ataxia-telangiectasia. Am J Ophthalmol 134:891-896.
Franchi L, Warner N, Viani K, Nuñez G (2009) Function of nod-like receptors in microbial recognition and host defense. Immunol Rev 227: $106-128$.

Giardino G, Fusco A, Romano R, Gallo V, Maio F, Esposito T, Palamaro L, Parenti G, Salerno MC, Vajro P, Pignata C (2013) Betamethasone therapy in a taxia t elangiectasia: unraveling the rationale of this serendipitous observation on the basis of the pathogenesis. Eur J Neurol 20:740-747.

Grabert K, Michoel T, Karavolos MH, Clohisey S, Baillie JK, Stevens MP, Freeman TC, Summers KM, McColl BW (2016) Microglial brain region-dependent diversity and selective regional sensitivities to aging. Nat Neurosci 19:504-516.

Guo Z, Kozlov S, Lavin MF, Person MD, Paull TT (2010) ATM activation by oxidative stress. Science 330:517-521.

Halle A, Hornung V, Petzold GC, Stewart CR, Monks BG, Reinheckel T, Fitzgerald KA, Latz E, Moore KJ, Golenbock DT (2008) The NALP3 inflammasome is involved in the innate immune response to amyloid- $\beta$. Nat Immunol 9:857-865.

Hanisch UK (2002) Microglia as a source and target of cytokines. Glia 40:140-155.

Hartlova A, Erttmann SF, Raffi FA, Schmalz AM, Resch U, Anugula S, Lienenklaus S, Nilsson LM, Kröger A, Nilsson JA, Ek T, Weiss S, Gekara NO (2015) DNA damage primes the type I interferon system via the cytosolic DNA sensor STING to promote anti-microbial innate immunity. Immunity 42:332-343.

Hui CW, Herrup K (2015) Individual cytokines modulate the neurological symptoms of ATM deficiency in a region specific manner. eNeuro 2:ENEURO.0032-15.2015

Hui CW, Song X, Ma F, Shen X, Herrup K (2018) Ibuprofen prevents progression of ataxia telangiectasia symptoms in ATM-deficient mice. J Neuroinflammation 15:308.

Ito K, Hirao A, Arai F, Matsuoka S, Takubo K, Hamaguchi I, Nomiyama K, Hosokawa K, Sakurada K, Nakagata N, Ikeda Y, Mak TW, Suda T (2004) Regulation of oxidative stress by ATM is required for self-renewal of haematopoietic stem cells. Nature 431:997-1002.

Jiang D, Zhang Y, Hart RP, Chen J, Herrup K, Li J (2015) Alteration in 5-hydroxymethylcytosine-mediated epigenetic regulation leads to Purkinje cell vulnerability in ATM deficiency. Brain 138:3520-3536.

Kongsui R, Beynon SB, Johnson SJ, Walker FR (2014) Quantitative assessment of microglial morphology and density reveals remarkable consistency in the distribution and morphology of cells within the healthy prefrontal cortex of the rat. J Neuroinflammation 11:182.

Kostura MJ, Tocci MJ, Limjuco G, Chin J, Cameron P, Hillman AG, Chartrain NA, Schmidt JA (1989) Identification of a monocyte specific preinterleukin 1 beta convertase activity. Proc Natl Acad Sci U S A 86: 5227-5231.

Kurz EU, Lees-Miller SP (2004) DNA damage-induced activation of ATM and ATM-dependent signaling pathways. DNA Repair 3:889-900.

Kwon D, Park E, Sesaki H, Kang SJ (2017) Carbonyl cyanide 3-chlorophenylhydrazone (CCCP) suppresses STING-mediated DNA sensing pathway through inducing mitochondrial fission. Biochem Biophys Res Commun 493:737-743.

Langfelder P, Horvath S (2008) WGCNA: an R package for weighted correlation network analysis. BMC Bioinformatics 9:559.

Lavin MF, Gueven N, Bottle S, Gatti RA (2007) Current and potential therapeutic strategies for the treatment of ataxia-telangiectasia. Br Med Bull 81- 82:129-147.

Lee JH, Paull TT (2007) Activation and regulation of ATM kinase activity in response to DNA double-strand breaks. Oncogene 26:7741-7748.

Li N, Banin S, Ouyang H, Li GC, Courtois G, Shiloh Y, Karin M, Rotman G (2001) ATM is required for $I \kappa B$ kinase (IKK) activation in response to DNA double-strand breaks. J Biol Chem 276:8898-8903.

Lugrin J, Martinon F (2018) The AIM 2 inflammasome: sensor of pathogens and cellular perturbations. Immunol Rev 281:99-114.

Lumsden JM, McCarty T, Petiniot LK, Shen R, Barlow C, Wynn TA, Morse HC 3rd, Gearhart PJ, Wynshaw-Boris A, Max EE, Hodes RJ (2004) Immunoglobulin class switch recombination is impaired in atm-deficient mice. J Exp Med 200:1111-1121.

Maréchal A, Zou L (2013) DNA damage sensing by the ATM and ATR kinases. Cold Spring Harb Perspect Biol 5:a012716.

Martinon F, Burns K, Tschopp J (2002) The inflammasome: a molecular platform triggering activation of inflammatory caspases and processing of proIL-beta. J Mol Cell 10:417-426. 
Matei IR, Guidos CJ, Danska JS (2006) ATM-dependent DNA damage surveillance in T-cell development and leukemogenesis: the DSB connection. Immunol Rev 209:142-158.

Mathur V, Burai R, Vest RT, Bonanno LN, Lehallier B, Zardeneta ME, Mistry KN, Do D, Marsh SE, Abud EM, Blurton-Jones M, Li L, Lashuel HA, Wyss-Coray T (2017) Activation of the STING-dependent type I interferon response reduces microglial reactivity and neuroinflammation. Neuron 96:1290-1302.e6.

McCool KW, Miyamoto S (2012) DNA damage-dependent NF-kappaB activation: NEMO turns nuclear signaling inside out. Immunol Rev 246:311-326.

McFarlin DE, Strober W, Waldmann TA (1972) Ataxia-telangiectasia. Medicine 51:281-314.

McGeer PL, McGeer EG (2015) Targeting microglia for the treatment of Alzheimer's disease. Expert Opin Ther Targets 19:497-506.

Menotta M, Biagiotti S, Bianchi M, Chessa L, Magnani M (2012) Dexamethasone partially rescues ataxia telangiectasia-mutated (ATM) deficiency in ataxia telangiectasia by promoting a shortened protein variant retaining kinase activity. J Biol Chem 287:41352-41363.

Mraz M, Stano Kozubik K, Plevova K, Musilova K, Tichy B, Borsky M, Kuglik P, Doubek M, Brychtova Y, Mayer J, Pospisilova S (2013) The origin of deletion $22 \mathrm{q} 11$ in chronic lymphocytic leukemia is related to the rearrangement of immunoglobulin lambda light chain locus. Leuk Res $37: 802-808$

Nowak-Wegrzyn A, Crawford TO, Winkelstein JA, Carson KA, Lederman HM (2004) Immunodeficiency and infections in ataxia-telangiectasia. J Pediatr 144:505-511.

Paller AS, Massey RB, Curtis MA, Pelachyk JM, Dombrowski HC, Leickly FE, Swift M (1991) Cutaneous granulomatous lesions in patients with ataxia-telangiectasia. J Pediatr 119:917-922.

Paludan SR, Bowie AG (2013) Immune sensing of DNA. Immunity 38: $870-880$.

Perlman S, Becker-Catania S, Gatti RA (2003) Ataxia-telangiectasia: diagnosis and treatment. Semin Pediatr Neurol 10:173-182.

Petersen AJ, Rimkus SA, Wassarman DA (2012) ATM kinase inhibition in glial cells activates the innate immune response and causes neurodegeneration in drosophila. Proc Natl Acad Sci U S A 109:E656-E664.

Peterson RD, Kelly WD (1964) Ataxia-telangiectasia: its association with a defective thymus. Lancet:1189-1193.

Prantner D, Perkins DJ, Lai W, Williams MS, Sharma S, Fitzgerald KA, Vogel SN (2012) 5,6-dimethylxanthenone-4-acetic acid (DMXAA) activates stimulator of interferon gene (STING)-dependent innate immune pathways and is regulated by mitochondrial membrane potential. J Biol Chem 287:39776-39788.

Quek H, Luff J, Cheung K, Kozlov S, Gatei M, Lee CS, Bellingham MC, Noakes PG, Lim YC, Barnett NL, Dingwall S, Wolvetang E, Mashimo T, Roberts TL, Lavin MF (2017a) A rat model of ataxia-telangiectasia: evidence for a neurodegenerative phenotype. Hum Mol Genet 26:109-123.

Quek H, Luff J, Cheung K, Kozlov S, Gatei M, Lee CS, Bellingham MC, Noakes PG, Lim YC, Barnett NL, Dingwall S, Wolvetang E, Mashimo T, Roberts TL, Lavin MF (2017b) Rats with a missense mutation in atm display neuroinflammation and neurodegeneration subsequent to accumulation of cytosolic DNA following unrepaired DNA damage. J Leukoc Biol 101:927-947.

Rathinam VA, Jiang Z, Waggoner SN, Sharma S, Cole LE, Waggoner L, Vanaja SK, Monks BG, Ganesan S, Latz E, Hornung V, Vogel SN, Szomolanyi-Tsuda E, Fitzgerald KA (2010) The AIM2 inflammasome is essential for host defense against cytosolic bacteria and DNA viruses. Nat Immunol 11:395-402.

Reiman A, Srinivasan V, Barone G, Last JI, Wootton LL, Davies EG, Verhagen MM, Willemsen MA, Weemaes CM, Byrd PJ, Izatt L, Easton DF, Thomp- son DJ, Taylor AM (2011) Lymphoid tumours and breast cancer in ataxia telangiectasia; substantial protective effect of residual ATM kinase activity against childhood tumours. Br J Cancer 105:586-591.

Renwick A, Thompson D, Seal S, Kelly P, Chagtai T, Ahmed M, North B, Jayatilake H, Barfoot R, Spanova K, McGuffog L, Evans DG, Eccles D; Breast Cancer Susceptibility Collaboration (UK), Easton DF, Stratton MR, Rahman N (2006) ATM mutations that cause ataxia-telangiectasia are breast cancer susceptibility alleles. Nat Genet 38:873-875.

Royer DJ, Carr DJ (2016) A STING-dependent innate-sensing pathway mediates resistance to corneal HSV-1 infection via upregulation of the antiviral effector tetherin. Mucosal Immunol 9:1065-1075.

Schatz DG, Swanson PC (2011) V(D)J recombination: mechanisms of initiation. Annu Rev Genet 45:167-202.

Scheiblich H, Schlütter A, Golenbock DT, Latz E, Martinez-Martinez P, Heneka MT (2017) Activation of the NLRP 3 inflammasome in microglia: the role of ceramide. J Neurochem 143:534-550.

Semlitsch M, Shackelford RE, Zirkl S, Sattler W, Malle E (2011) ATM protects against oxidative stress induced by oxidized low-density lipoprotein. DNA Repair 10:848-860.

Shiloh Y (2003) ATM and related protein kinases: safeguarding genome integrity. Nat Rev Cancer 3:155-168.

Suberbielle E, Sanchez PE, Kravitz AV, Wang X, Ho K, Eilertson K, Devidze N, Kreitzer AC, Mucke L (2013) Physiologic brain activity causes DNA double-strand breaks in neurons, with exacerbation by amyloid-beta. Nat Neurosci 16:613-621.

Thornberry NA, Bull HG, Calaycay JR, Chapman KT, Howard AD, Kostura MJ, Miller DK, Molineaux SM, Weidner JR, Aunins J (1992) A novel heterodimeric cysteine protease is required for interleukin- $1 \beta$ processing in monocytes. Nature 356:768-774.

Thornton P, Pinteaux E, Gibson RM, Allan SM, Rothwell NJ (2006) Interleukin-1-induced neurotoxicity is mediated by glia and requires caspase activation and free radical release. J Neurochem 98:258-266.

Torres-Platas SG, Comeau S, Rachalski A, Bo GD, Cruceanu C, Turecki G, Giros B, Mechawar N (2014) Morphometric characterization of microglial phenotypes in human cerebral cortex. J Neuroinflammation 11:12.

Valentin-Vega YA, Maclean KH, Tait-Mulder J, Milasta S, Steeves M, Dorsey FC, Cleveland JL, Green DR, Kastan MB (2012) Mitochondrial dysfunction in ataxia-telangiectasia. Blood 119:1490-1500.

Westbrook AM, Schiestl RH (2010) Atm-deficient mice exhibit increased sensitivity to dextran sulfate sodium-induced colitis characterized by elevated DNA damage and persistent immune activation. Cancer Res 70:1875-1884.

Williamson CD, Wong DS, Bozidis P, Zhang A, Colberg-Poley AM (2015) Isolation of endoplasmic reticulum, mitochondria, and mitochondriaassociated membrane and detergent resistant membrane fractions from transfected cells and from human cytomegalovirus-infected primary fibroblasts. Curr Protoc Cell Biol 68:3.27.1-33.

Wu Q, Combs C, Cannady SB, Geldmacher DS, Herrup K (2000) Betaamyloid activated microglia induce cell cycling and cell death in cultured cortical neurons. Neurobiol Aging 21:797-806.

Yang YG, Lindahl T, Barnes DE (2007) Trex1 exonuclease degrades ssDNA to prevent chronic checkpoint activation and autoimmune disease. Cell 131:873-886.

Yang Y, Hui CW, Li J, Herrup K (2014) The interaction of the atm genotype with inflammation and oxidative stress. PLoS One 9:e85863.

Zannolli R, Buoni S, Betti G, Salvucci S, Plebani A, Soresina A, Pietrogrande MC, Martino S, Leuzzi V, Finocchi A, Micheli R, Rossi LN, Brusco A, Misiani F, Fois A, Hayek J, Kelly C, Chessa L (2012) A randomized trial of oral betamethasone to reduce ataxia symptoms in ataxia telangiectasia. Mov Disord 27:1312-1316. 